\title{
A New Approach to Study the Degradation of the Organic Pollutants by A-Doped MxOy/B Photocatalysts
}

\section{Mojtaba Arabameri}

University of Kashan

Hadis Bashiri ( $\sim$ h.bashiri@ymail.com )

University of Kashan https://orcid.org/0000-0002-1049-7984

\section{Research Article}

Keywords: Photodegradation, Organic pollutants, Comprehensive mechanism, Reactive-centers, Effective charge carriers, Hybrid manual-automatic method

Posted Date: September 27th, 2021

DOI: https://doi.org/10.21203/rs.3.rs-885999/v1

License: (c) (i) This work is licensed under a Creative Commons Attribution 4.0 International License. Read Full License

Version of Record: A version of this preprint was published at Environmental Science and Pollution Research on January 31st, 2022. See the published version at https://doi.org/10.1007/s11356-02218923-7. 


\section{A New Approach to Study the Degradation of the $\quad 1$}

\section{Organic Pollutants by A-doped $\mathrm{M}_{\mathrm{x}} \mathrm{O}_{\mathrm{y}} / \mathrm{B}$}

\section{Photocatalysts}

Department of Physical Chemistry, Faculty of Chemistry, University of Kashan, Kashan, Iran 6

*To correspondence should be addressed. Fax: +98 3155912397. 
$\begin{array}{ll}\text { Abstract } & 16\end{array}$

This work presents a new approach and a comprehensive mechanism to study the kinetics of

the photodegradation of the organic pollutants. The vital role of various operational factors on

the degradation of the organic pollutants is explained using this method. The proposed approach is based on the simple strategies and a powerful computational method. Two new variables "the effective concentration of photon" $\left(I_{\mathrm{eff}}\right)$ and "the effective concentration of the reactive-centers" (RC) are defined to better understanding the effect of operational parameters on the organic pollutants photodegradation. The optimum conditions of the photocatalytic degradation can be determined with the help of this method. This approach was used to study the kinetics of photodegradation of the organic pollutants on the $A-\operatorname{doped} \mathrm{M}_{\mathrm{x}} \mathrm{O}_{\mathrm{y}} / \mathrm{B} 25$ photocatalysts. The provided mechanism has been examined with the some experimental data. The high correlations between the experimental data and the fitting results under different conditions prove this mechanism could be reliable.

Keywords: Photodegradation; Organic pollutants; Comprehensive mechanism; Reactive- 30 centers; Effective charge carriers; Hybrid manual-automatic method. 


\section{Introduction}

Water is one of the essential needs of all life-supporting processes (Westall \&Brack 2018). One

of the most important challenges of today's society is providing safe drinking water for all

pollution due to the growth of the various pollutant activities such as industrial waste effluents, dyes are among the major pollutants of water because of their toxic and carcinogenic characteristics (Lai et al. 2014).

The results of various researches show that advanced oxidation processes (AOPs) are suitable techniques for removing toxic materials (Ghatak 2014, Navarro et al. 2017, Samadi et al. 2017, Stets et al. 2018, Zhou et al. 2019). This technique is based on the in situ production of strong oxidizing intermediates such as superoxide radical anions $\left(\mathrm{O}_{2}^{--}\right)$, hydroxyl radicals $\left(\mathrm{OH}^{\bullet}\right)$, hydrogen peroxide $\left(\mathrm{H}_{2} \mathrm{O}_{2}\right)$, and singlet oxygen $\left({ }^{1} \mathrm{O}_{2}\right)$. AOPs include the different types of processes such as the chemical $\left(\mathrm{Fe}^{2+} / \mathrm{H}_{2} \mathrm{O}_{2}, \mathrm{O}_{3} / \mathrm{H}_{2} \mathrm{O}_{2}\right)$, the photochemical $\left(\mathrm{UV} / \mathrm{H}_{2} \mathrm{O}_{2}\right.$, $\left.\mathrm{UV} / \mathrm{O}_{3}, \quad \mathrm{UV} / \mathrm{Fe}^{2+} / \mathrm{H}_{2} \mathrm{O}_{2}, \quad \mathrm{UV} / \mathrm{TiO}_{2}\right)$, the son-chemical $\left(\mathrm{UV} / \mathrm{H}_{2} \mathrm{O}_{2}, \quad \mathrm{UV} / \mathrm{O}_{3}\right)$ and the electrochemical technologies (Al-Kdasi et al. 2004, Vag1 \&Petsas 2017).

Heterogeneous photocatalysis is an advanced technology to deal with environmental 
(Sabouri et al. 2018), CdS (Khan et al. 2016), and $\mathrm{WO}_{3}$ (Yao et al. 2017) have been 58

widely studied for the decomposition of the organic contaminants under visible light and UV 59 irradiation. Titanium dioxide and zinc oxide have received much attention in the field of 60 pollutants photodegradation research. These photocatalysts are non-toxic, low-cost, highly 61 efficient, and environmentally friendly (Xia et al. 2016).

In general, a photocatalytic process involves the following steps: (1) photon absorption 63 with energy equal to or greater than the bandgap of the semiconductor, (2) the electron transfer 64 from the valence band (VB) to the conduction band (CB) for the producing electron-hole pairs, (3) the trapping of the charge carriers on the effective reactive-centers during light illumination, and (4) the degradation of toxic compounds by the powerful oxidizing agents:

$$
\begin{aligned}
& \mathrm{A}-\text { doped } \mathrm{M}_{\mathrm{x}} \mathrm{O}_{\mathrm{y}} / \mathrm{B}+\mathrm{h} v \rightarrow \mathrm{e}^{-}+\mathrm{h}^{+} \\
& \mathrm{e}^{-}+\mathrm{h}^{+}+\text {The effective reactive }- \text { centers } \rightarrow \text { The powerful oxidizing agents } \\
& \text { The powerful oxidizing agents }+ \text { Pollutant } \rightarrow \text { Intermediates }
\end{aligned}
$$

Although the kinetics of photocatalytic reactions have been extensively investigated, more 68 work is needed to gain the sufficient knowledge about the mechanism of these reactions. Many researchers have investigated the mechanism of photocatalytic reactions based on experiment results, identification of the reactive oxygen species, and studying the behavior of the reaction intermediates (Berberidou et al. 2016, Dror et al. 2020, El Mragui et al. 2019, Kaur \&Sud 2012).

To the best of our knowledge, some articles have discussed the mechanism of the 74 photocatalytic reactions, and they have proposed the general mechanisms or the possible 75 pathways for photocatalytic reactions (Huang et al. 2020, Turkten \&Cinar 2017, Wang et al. 2018). Some articles have studied the kinetics of the photocatalytic process based on a proposed mechanism (Emeline et al. 2000, Minero et al. 2013, Montoya et al. 2014). Unfortunately, the detailed mechanism at the atomic scale has been introduced for a limited number of 
photocatalysts (Nosaka \&Nosaka 2017). However, only few articles describe the 80 photodegradation mechanism involving the elementary steps of the reaction and their rate

In this paper, a new approach was proposed to study the kinetics and mechanism of the degradation of the organic pollutants by the various photocatalysts under UV-Vis light the pollutants photodegradation.

Our approach assumes the photodegradation of organic compounds occurs due to the effective charge carriers and the formation of the effective reactive-centers on the $\mathrm{A}-$ doped $\mathrm{M}_{\mathrm{x}} \mathrm{O}_{\mathrm{y}} / \mathrm{B}$ surface. Therefore, the two variables named the effective concentration of photon $\left(I_{\text {eff }}\right)$ and effective concentration of the reactive-centers $(\mathrm{RC})$ are defined for a better understanding the effect of operational parameters on pollutants photodegradation. Because a small number of the reactive-centers and the charge carriers lead to the degradation of organic pollutant. Interestingly, these variables reach the maximum or minimum when the system is in optimal condition.

The $\mathrm{A}$ - doped $\mathrm{M}_{\mathrm{x}} \mathrm{O}_{\mathrm{y}} / \mathrm{B}$ general formula was proposed to demonstrate the flexibility of 100 our method. The $\mathrm{M}_{\mathrm{x}} \mathrm{O}_{\mathrm{y}}$ is a semiconductor, such as $\mathrm{TiO}_{2}$ and $\mathrm{ZnO}$, which can interact with 101 water species, oxygen molecules, and other materials to form the various reactive-centers. A is a metallic or non-metallic element that can increase the photocatalytic activity of the $\mathrm{M}_{\mathrm{x}} \mathrm{O}_{\mathrm{y}}$ photocatalyst. 
The interaction of water species and the pollutant molecules with the $A-\operatorname{doped} \mathrm{M}_{\mathrm{x}} \mathrm{O}_{\mathrm{y}} / \mathrm{B}$ to the production of the reactive-centers for the degradation of organic pollutant molecules.

The B component can be a compound such as graphic carbon nitride, reduced graphene water species, leads to the formation of the other reactive-centers. The coupling these materials with a photocatalyst can be a suitable method to achieve enhanced photocatalytic activity.

In the present investigation, MATLAB software was used as a computational tool to solve the role of various operational parameters in the photodegradation of pollutants was easily explained using this approach. The values of rate constants for elementary reactions and the examined under different operating conditions.

The production of the electron-hole pairs, dye adsorption on the photocatalyst surface, the trapping of the charge carriers to produce the reactive radicals, and the recombination of the charge carriers have the key effects on the photodegradation of the organic pollutants. In this study, a proposed approach has been used to theoretically investigate the effects of these factors on the degradation process of the organic pollutants without using the common kinetics approximations. Therefore, a non-approximation approach is proposed to study the kinetics 
obtained using the proposed mechanism and the kinetics approximations such as the steady-

state approximation. This complex kinetics equation can be reduced to a Langmuir-

Hinshelwood equation by considering more approximations. It is not possible to solve this equation.

The real mechanism of the photodegradation of organic pollutants involves several steps, experimental conditions including the type of reactants, the solution $\mathrm{pH}$, the concentration of reactants, and the photocatalyst surface structure. A suitable method for studying the mechanism of the photocatalytic reactions is to estimate the rate constants and to investigate the effect of different factors on their values. A detailed understanding of the photodegradation process of the organic pollutants by photocatalysis helps us to properly design a photocatalytic experiment. However, this approach provides more information about the generation process of the electron-hole pairs. On the one hand, the importance of our work is that it proposes the rate constants of a photocatalytic process without any approximation. The different samples and the rate constants of the other steps is provided by a proposed variable named as "the effective concentration of photons".

\section{Methods: the estimation of the rate constants and the effective variables}

The mechanism of a chemical reaction consists of a series of elementary chemical reactions. 
parameters estimation procedures. Mathematical methods for studying the kinetics and mechanisms of chemical reactions can be stochastic or deterministic.

The stochastic method regards the time evolution of the chemical reaction as a randomwalk process that is described by a differential equation (the chemical master equation) (Bashiri \&Mohamadi 2016, Bashiri \&Pourbeiram 2016, Rafiee \&Bashiri 2019, 2020b, a, Shams Ghamsari \&Bashiri 2020). The deterministic method regards time evolution of the chemical system as a continuous process that can be governed by a series of coupled ordinary differential equations (ODEs). In our work, the deterministic method was used to solve a series of rate equations that describe the photocatalytic process. The fitting data of the organic pollutants concentration versus time are obtained by integration of the ODEs. For the implementation of the deterministic method, the numerical techniques can be used to solve the differential rate equations. The results of various researches showed that the performance of stochastic and 165 deterministic methods strongly depends on the studied system (Lerkkasemsan 2010, Safieddine et al. 2012, Zheng \&Ross 1991).

We used MATLAB code framework based on the following parts: (1) experimental data, 168 initial concentrations, and initial guesses of rate constants are the inputs, (2) the rate equations of the elementary steps are written, (3) odes 15 s solver is used (4) the commands for the drawing 170 curves are used, (5) the codes related to the minimization are applied.

MATLAB software uses various solvers such as ode23, ode45, ode15s, ode23s, and ode113 to solve the ODEs. Ordinary differential equations can be classified as stiff and nonstiff. Shampine et al. (Shampine \&Reichelt 1997) believed that this classification plays a crucial role in selecting the solvers. Stiffness is an essential and efficient concept in the numerical integration of the ODEs. It is generally accepted that a differential equation is stiff if the explicit numerical methods do not provide the appropriate solutions to the given equation. The stiffness phenomenon depends on the initial conditions, the ordinary differential equations, 
and the numerical algorithm. Some algorithms are defined for non-stiff equations and some others for stiff equations.

MATLAB documentation suggests the ode 45 is the best solver for solving problems in the first step. Many problems have been solved by the ode45 solver, which is based on a RungeKutta method (Forsythe 1977). The next suggestion is that the ode15s solver can be used if the ode45 fails or is extremely slow. In this work, the integration of the ODEs was performed by using the ode15s solver from MATLAB version, R2015b. The ode15s is a variable-order and on the implementing of the backward differences of a set of numerical differentiation formulas (NDFs) (Shampine \&Reichelt 1997).

Several numerical methods such as Euler, Runge-Kutta, Adams-Bashforth, and Adams189 Moulton are used for solving the system of differential equations. These methods are divided 190 into two categories single-step and multi-step methods. The Backward difference formula (BDF) is a general method for solving stiff differential equations. The BDFs are a set of 192 implicit methods for the numerically solving of the differential equations. A system of differential equations can be written as follows:

$$
F\left(t \cdot x(t) \cdot x^{\prime}(t)\right)=0 ; x\left(t_{0}\right)=x_{0}
$$

The simplest BDF method is the Backward Euler method, which involves replacing the $\mathrm{x}$ derivative by a backward difference:

$$
F\left(t_{\mathrm{n}}, x_{\mathrm{n}}, \frac{x_{\mathrm{n}}-x_{\mathrm{n}-1}}{h}\right)=0 ; h=t_{\mathrm{n}}-t_{\mathrm{n}-1}
$$

Where $h$ is the step size. MATLAB implements an ode15s solver based on the BDF method.

Therefore, MATLAB solves the ODEs using the ode15s algorithm in this work. Then, the 
Generally, the rate constants for each step and the effective variables are the adjustable parameters obtained through the fitting process in the MATLAB environment. In this study, of parameters in two steps: (1) the rate constants and initial concentrations of the reactivecenters are manually adjusted to obtain a coefficient of determination close to 1 ; (2) the order gradient methods. The interior-point algorithm solves a sequence of unconstrained minimization problems to approach the constrained optimization.

In this work, the sum of squared errors (SSE) between the fitted and experimental data is used as an objective function of the optimization process.

$$
\text { Objective function }=\operatorname{SSE}=\sum\left(x_{\text {pred }}(i)-x_{\exp }(i)\right)^{2}
$$

Where, the variables $x_{\text {pred }}$ and $x_{\exp }$ are the predicted and experimental data of $\mathrm{x}$, respectively. In each run, the program calculates the coefficient of determination ( $R$-square) using the meansquare error for easy comparison of the results. The coefficient of determination of the

$$
R^{2}=1-\left(\frac{\mathrm{SSE}}{\mathrm{SST}}\right)
$$

Where, SST is the total sum of squares (variance), which is obtained as follows: 


$$
\mathrm{SST}=\sum\left(x_{\exp }(i)-\bar{x}(i)\right)^{2}
$$

Where, $\bar{x}$ is the mean of the experimental data.

\section{Results and Discussion}

\subsection{Basics of the proposed approach}

The photodegradation process of the pollutant depends on several intrinsic and extrinsic

factors. The photocatalyst properties such as surface area, crystallinity, morphology, and the

doping of other elements into its lattice refer to the intrinsic factors (Friedmann et al. 2010).

The other factors such as irradiation light source, the concentration of organic pollutants, related to extrinsic factors (Wan et al. 2014).

The interaction of the catalyst with other substances in the solution under UV/vis light illumination leads us to define a set of the reactive-centers on the photocatalyst surface. The basic assumption of our approach is that photodegradation process is controlled by the effective reactive-centers on the surface of the photocatalyst. The formula of the reactivecenters is shown in Table 2 .

In addition, the proposed approach is based on several other strategies as follows: (1) effective concentration of photon and the effective concentration of the reactive-centers can be considered as an efficiency criterion of the photocatalytic process, (2) the trapping the photogenerated electrons and holes plays a vital role in the degradation of organic pollutants,

(3) the adsorption of dissolved species on the catalyst surface is one of the crucial factors in the photocatalytic activity, (4) surface-adsorbed radicals $\left(\mathrm{OH}^{\bullet}\right.$ (ads) and $\mathrm{O}_{2}^{-\bullet}$ (ads)) are main reactive species formed in the photodegradation process, (5) the doping of the other elements into the photocatalyst lattices can significantly promote the destruction of the organic pollutants 
on the performance of the degradation reaction, (7) intermediates have a crucial effect on the

rate of organic pollutants degradation due to the simultaneous reaction with reactive oxygen

species formed in the solution.

As shown in Figure 1, our approach to the photodegradation of organic pollutants involves the following steps: (1) a certain number of the reactive-centers are defined on the surface of the $\mathrm{TiO}_{2}$, (2) based on the proposed model, the reaction pathway is decomposed into a series of elementary reactions, (3) a suitable software with high computing power (MATLAB) is selected, (4) an initial value is suggested for each the rate constant, and the effective 254 concentration of the reactive-centers, (5) the required codes were written in MATLAB 255 environment to run the data fitting process, (6) the data fitting program was performed to 256 examine the reaction mechanism, (7) the fitted and experimental data were compared by 257 plotting the pollutant concentration versus time and computing the $R^{2},(8)$ if the fitting is not 258 right, the kinetics factors (elementary steps and the rate constants) or the effective 259 concentration of reactive-centers will be changed, (9) the fitting process is terminated when the 260 best fitting is obtained. In other words, an initial mechanism is constructed based on the proposed approach. The fitting codes are written in a MATLAB computing environment.

The reliable fitting results are obtained by adjusting the rate constants of the elementary 263 steps and the concentrations of the reactive-centers. If a good fit is not found, another 264 mechanism should be proposed. The initial guess for the rate constants is generated using the 265 literature's values (Bashiri et al. 2014) or our suggested values.

However, it is impossible to propose a unique and comprehensive mechanism for 267 photocatalytic reactions due to the various factors and their influence on the degradation 268 process. Therefore, to obtain the best conformity between the experimental and the simulated 269 data, it is necessary to examine the different mechanisms of pollutant degradation. 
In general, three categories of mechanisms have been proposed for the degradation of organic pollutants by photocatalysts under UV-Vis light.

In the first category of mechanisms, the hydroxyl radicals are the main oxidant of the pollutant's degradation. Achieving this mechanism requires the production of powerful holes.

These holes are produced by the action of the UV-light on the surface of a photocatalyst with the suitable bandgap. The systems of the $\mathrm{TiO}_{2} / \mathrm{UV}$, Ni-doped $\mathrm{ZnO} / \mathrm{UV}$, and Fe-doped $\mathrm{TiO}_{2} / \mathrm{UV}$ are considered in this category.

In the second category of mechanisms, the superoxide radicals are the main oxidant of the pollutant degradation. In these systems, there are not powerful photogenerated holes to oxidize the water species. The systems of the $\mathrm{TiO}_{2} / \mathrm{Vis}-$ light, $\mathrm{N}-\mathrm{TiO}_{2} / \mathrm{Vis}-$ light, and $\mathrm{N}-\mathrm{TiO}_{2} / \mathrm{RGO} / \mathrm{Vis}-$ light are in the second category of the mechanisms.

For non-doping $\mathrm{TiO}_{2}$ under visible light irradiation, it has been suggested (Liu et al. 2000) that an adsorbed pollutant molecule is excited to the singlet or triplet states; subsequently an electron is injected from the excited pollutant molecule to the $\mathrm{TiO}_{2}$ conduction band to produce a pollutant cationic radical $\left(\right.$ pollutant ${ }^{\bullet+}$ ). This excited molecule undergoes the degradation process to produce the intermediates. The visible-light-induced electrons react with $\mathrm{O}_{2}$ molecules and produce the superoxide radicals. This mechanism is also called the photosensitized oxidation mechanism.

When $\mathrm{N}$-doped $\mathrm{TiO}_{2}$ or $\mathrm{N}$-doped $\mathrm{TiO}_{2} / \mathrm{RGO}$ are exposed by the visible light irradiation, the photogenerated electrons are transferred from the localized $\mathrm{N}$ levels in the $\mathrm{TiO}_{2}$ band gap (the mid-gap states) to the conduction band. These electrons in the conduction band are trapped by the $\mathrm{O}_{2}$ pre-adsorbed on the $\mathrm{TiO}_{2}$ surface or the RGO surface to produce the superoxide radicals. 
The electron spin resonance (ESR) experiments using the spin-trap, 5,5- 296 dimethylpyrroline-1-oxide (DMPO), showed (Rengifo-Herrera et al. 2009) the oxidative 297 potential of the photoinduced holes associated with the mid-gap states have not high power to 298 produce the hydroxyl radicals $(2.38 \mathrm{~V}(\mathrm{SHE}))$. Some researchers ignore this argument and 299 consider the reaction of water species to visible light-induced holes (Chen \&Liu 2016). For the 300 systems of the $\mathrm{N}$-doped $\mathrm{TiO}_{2}$ and $\mathrm{N}$-doped $\mathrm{TiO}_{2} / \mathrm{RGO}$, the reaction of the visible-light-induced 301 holes with water species was neglected in our method. However, the reaction of the holes with 302 the adsorbed pollutant molecules on the photocatalyst surface is considered.

In the third category of mechanisms, the free photogenerated holes are the main factor of 304 degradation of organic pollutants. In some systems that follow the first type mechanism, adding 305 new material to the photocatalyst structure may change the main oxidant. For example, the 306 presence of the ozone in the Ag-doped $\mathrm{ZnO} / \mathrm{UV}$ photocatalyst plays this role.

The general proposed framework for the mechanism of the degradation process of the 308 organic pollutants in $\left(\mathrm{A}-\right.$ doped $\left.\mathrm{M}_{\mathrm{x}} \mathrm{O}_{\mathrm{y}} / \mathrm{B} / \mathrm{UV}-\mathrm{Vis}\right)$ aqueous systems is shown in Table 3. 309 In the present study, several mechanisms were examined, and among them, the final 310 mechanism presented in Table 4 had the best agreement with the experimental data. Three 311 general conclusions can be deduced from the final mechanism: (1) a general framework can be proposed for the degradation process of organic pollutant by the photocatalysts; (2) the rate constants of the elementary reactions in different systems have similar values; (3) the excellent conformity in the fitting process indicates that the proposed approach can be verified using the 315 experimental data (Han et al. 2018, Mousavi et al. 2017, Peng et al. 2019, Tang et al. 2018) 316 under different conditions.

Two methods of the optimization and manual adjustment were implemented simultaneously for the $\mathrm{TiO}_{2} /$ visible light/TC system to compare the correlation results (Figure 2). The correlation analysis on the fitting results shows that there is not much difference 
between the $R^{2}$ values in the optimization and the manual adjustment methods. For this system,

the elementary reaction steps and their rate constants are presented in Table 5. Perfect

conformity between the adjusted and optimized values was found in this Table. This result

shows that the MATLAB optimization method can be used well for simple systems.

However, the fitting results show that manual adjustment of the parameters leads to reliable values than the optimization-based procedure for the complicated systems. The main

reasons can be explained as follows: (1) the number of parameters estimated in each run is

large, (2) many operational factors are considered for the selecting of an appropriate mechanism, (3) the detailed mechanism of photocatalytic reactions involves many elementary steps. For this reason, we proposed a hybrid manual-automatic method.

3.2.1. The analysis of the curve of pollutant concentration versus time and the effect of the

The analysis of the plot of the concentration versus time is slightly complicated. The shape of this curve qualitatively reflects the behavior of the photocatalytic system. In general, the curves of pollutant concentration versus time can be divided into three steps. In the first step, the ROSs mainly react with the organic pollutant molecules. The fitting investigations show that in the initial times, the curve of organic pollutant concentration versus time is mainly affected by the interaction between the pollutant and ROSs. In other words, regardless of the intermediates reaction with the $\mathrm{OH}^{\bullet}$ radicals, only the initial parts of the fitting curve have good conformity to the experimental points. The reaction of ROSs with the initial intermediates, which is produced in the photocatalytic process, is considered as the second step. The effect of other intermediates are taken into account in the third step.

From this view, the two types of mechanisms can be defined: degradation mechanism 
concentration vs. time at the initial times. The other type shows more agreement between the experimental and the fitting results after passing the time. In other words, a set of consecutive reactions occurs in which the produced intermediates are oxidized by the ROSs. The number of these reactions in the real system is large, but one or two reactions can be appropriate to obtain a good agreement. The rate constant of these consecutive reactions depend on the conditions of the studied system. After passing the time, the interaction between the intermediates of the degradation of organic pollutants and ROSs is also influential.

However, the steps of the hybrid manual-automatic adjusting of the system parameters and the concentrations of reactive centers can be explained as follows: (1) Based on the experimental results, the percentage of the ROSs participation in the pollutant degradation is approximately adjusted. The fitting process starts without considering the intermediates reactions. The values of the effective variables should be adjusted, and the fitting results should be as close as possible to the first experimental data. (2) the reaction of the first intermediate with the ROSs is considered, and the program is executed. The rate constant of this step is adjusted to obtain good conformity between the model predictions and the other experimental points. (3) the reactions of one or more intermediates with the ROSs are considered to obtain the excellent fitting results. (4) finally, the values of the rate constants are optimized by using the fminsearch function.

The fitting results show the first intermediate competes significantly with the organic pollutant molecule to consume the hydroxyl radicals. These reactions are symbolically represented in the fifth part of the general mechanism. The rate constant of the consecutive 
intermediates tends to react with the ROSs, the rate constant for these reactions varies slightly for the samples under study.

In this paper, four systems have been considered to examine the comprehensive mechanism of the degradation of the organic pollutant on the surface of the photocatalysts under different conditions. Figures 3 and 4 represent the fitting results for the studied samples.

Figure 3 shows the trend of changes in the effective concentration of photon and the effective concentration of reactive-centers based on the proposed approach. In an overview, Figures 3 and 4 show that there are significant correlations between degradation efficiencies and the different parameters. In this paper, The effect of some operational parameters on the degradation efficiency will be discussed using these figures.

\subsubsection{The production step of the photogenerated charge carriers}

The first part of the proposed framework is the production of the charge carriers. Similar to other photocatalytic reactions (Galindo et al. 2000, Rauf et al. 2011), the proposed mechanism is initiated by photoexcitation of the photocatalyst or the pollutant under the UV-Vis light illumination. This step is very fast with a timescale in the order of $10^{-14} \mathrm{~s}$ (Dou et al. 2004, Friedmann et al. 2010). Nevertheless, our results showed the rate constant for the may be that UV beams are more powerful than visible light. However, it seems that there is a mismatch between the timescale of charge carriers generation and the relatively low efficiency of photocatalytic reactions (Qian et al. 2019). This conclusion is an interesting result, because 
photodegradation can result from a balance between the processes of adsorption, recombination, trapping, and interfacial transfer of the charge carriers.

As a result, the generation of effective electrons and holes is the first step in the proposed mechanism. For this reason, the rate constant of the production of the effective charge carriers may be reduced. Based on these arguments, the proposed approach assumes that a significant 398 fraction of the incident light beams is scattered into the reaction vessel and does not lead to the 399 generation of electrons and holes. Therefore, a minor fraction of the photogenerated carriers 400 leads to degradation of the organic pollutant due to performance-limiting factors such as the 401 recombination process and the photoreactor geometry. In other words, small number of 402 electron-hole pairs generated by the intensity of the absorbed light contribute to the destruction 403 of organic pollutant, and many of them are ineffective. This discussion proposes two variables, 404 which are named as the effective concentration of photon $\left(I_{\text {eff }}\right)$, and the effective concentration 405 of reactive-centers $(\mathrm{RC})$.

These variables depend on the system operational parameters, such as the initial pollutant 407 concentration, photocatalyst loading, light intensity, the solution $\mathrm{pH}$, and the volume of the 408 reaction vessel. The effective concentration of photon refers to the effect of the charge carriers 409 in the pollutant degradation. Besides, the effective concentration of reactive-centers indicates 410 the role of the photocatalyst and its interaction with the other dissolved species in the degradation process. In our approach, the effective reactive-centers refer to the sites that play a direct role in the destruction of the organic pollutant. The structure and effective concentration of the reactive-centers depend on the following factors: (1) the structure of the photocatalyst; (2) the $\mathrm{pH}$ of the solution; (3) the species dissolved in the solution.

The $\mathrm{pH}$ of the solution is a critical parameter in the degradation of the pollutants under $\mathrm{UV} /$ visible irradiation. Because the medium $\mathrm{pH}$ determines the charges on the catalyst surface and the organic pollutant molecules. It is affected by various factors such as the charge values 
on the semiconductor surface and organic pollutant molecules, ROSs concentration formed during the destruction process, and the aggregates' size. The influence of $\mathrm{pH}$ on the researchers (Alkaim et al. 2014, Kazeminezhad \&Sadollahkhani 2016). Therefore, the structure of the reactive-centers depends on the solution's $\mathrm{pH}$. In some cases, the degradation rate of the cationic organic pollutants in an acidic medium is greater than that of an alkaline solution (Devi et al. 2017). In the proposed method, this behavior is ascribed to the increase in the concentration of the hydroxyl groups originated from the interaction of the protons (or water molecules) with the surface oxygen sites.

For the $\mathrm{A}-$ doped $\mathrm{M}_{\mathrm{x}} \mathrm{O}_{\mathrm{y}} / \mathrm{B}$ photocatalyst, the concentration of reactive-centers of $\mathrm{M}-\mathrm{OH}_{2}^{+}, \mathrm{M}-\mathrm{O}_{\text {bridge }} \mathrm{H}-\mathrm{M}, \mathrm{A}-\mathrm{OH}_{2}^{+}$, and $\mathrm{A}-\mathrm{O}_{\text {bridge }} \mathrm{H}-\mathrm{A}$ increases in the acidic $\mathrm{pH}$ due to the availability of sufficient protons. Also, the concentration of the $\mathrm{M}-\mathrm{OH}, \mathrm{M}-\mathrm{O}^{-}, \mathrm{A}-$ $\mathrm{OH}$, and $\mathrm{A}-\mathrm{O}^{-}$reactive-center increases at alkaline conditions. In a neutral medium, the reactive-centers produced by the interaction between non-dissociated water molecules and the $\mathrm{M}_{\mathrm{x}} \mathrm{O}_{\mathrm{y}}$ surface are responsible for the degradation of the organic pollutant. It is worth noting that if A was not a metallic element, there is no effective interaction between this component and water species. The effective variables, especially $I_{\text {eff }}$, can be used to determine optimal operating conditions. During the fitting process, the rate constants, $I_{\text {eff }}$ values, and the effective concentration of reactive-centers are adjusted simultaneously to obtain the best fitting between the experimental data and simulated results. Two significant results are obtained by the plotting of $I_{\text {eff }}$ data against the values of operational parameters: (1) the optimum 
The second part of the proposed mechanism refers to the adsorption process. The adsorption

of the pollutant on the catalyst surface is one of the important factors in photocatalysis ( $\mathrm{Li}$ et dependent (Grzechulska \&Morawski 2002). In this work, the adsorption process refers to the adsorption of organic pollutant molecules on the catalyst surface during the photocatalytic reaction.

As seen in Tables 4 and 5, the values of the rate constants for the adsorption step indicate the following comments. (1) The pollutant adsorption on the surface of the photocatalyst under visible light irradiation plays a more prominent role in the degradation process; (2) the amount of TC adsorbed on the $\mathrm{N}-\mathrm{TiO}_{2} / \mathrm{RGO}$ surface was high in the dark (without light) due to the factor to initiate the photodegradation process under visible light; (4) based on the mechanism proposed in Table 5, TC adsorbed on the $\mathrm{TiO}_{2}$ surface can be an important factor for the transfer of electrons to the $\mathrm{TiO}_{2}$ conduction band ( $\mathrm{Li}$ et al. 2014). These observations are in agreement with the experimental results.

However, the fitting results indicate the critical role of the AOPs in the high degradation of the pollutants. The following possible reasons can be used to explain these results: (1) the powerful holes are produced in the photocatalyst/UV-light system that can rapidly oxidize the pollutants. Therefore, adsorption seems to be less important in these conditions. The experimental results show that only $3.51 \%$ of the CR concentration and $5.31 \%$ of the AO7 concentration were decreased during the dark adsorption (Han et al. 2018, Peng et al. 2019).

However, the nature of the dark adsorption is different from the adsorption process during 
surface, they might be more easily oxidized by the valance band holes or ROSs (Hossain et al.

2018). The adsorption step of organic pollutant on the $\mathrm{TiO}_{2}$ surface is one of the elementary follows: " the degradation of the adsorbed pollutant after light irradiation and then the adsorption of new molecules on the photocatalyst surface."

The trend of changes in the concentration of the adsorption sites obtained from the fitting 2000, Yu et al. 2000), the fitting results indicate that increasing the number of adsorption sites improves the pollutant degradation on the photocatalyst surface. A relative correlation is observed between the degradation efficiency and the adsorption of the pollutant on the photocatalyst surface. The enhanced photocatalytic performance of the $3 \mathrm{wt} . \% \mathrm{Fe}$-doped $\mathrm{TiO}_{2}$ (100 mg.L $\mathrm{L}^{-1}$, pH=3), 3 wt.\% Ni-doped $\mathrm{ZnO}$, and $\mathrm{N}$-doped $\mathrm{TiO}_{2} / \mathrm{RGO}$ compared to the other samples could be ascribed to the adsorption ability increasing of these catalysts. In agreement with the experimental results, the effective concentration of adsorption sites in N-doped $\mathrm{TiO}_{2} / \mathrm{RGO}$ is increased in virtue of the presence of $\mathrm{RGO}$.

It was found (Sathishkumar et al. 2011) that the catalysts with the higher surface areas provide more reactive-centers, which could increase the organic pollutant adsorption and the incident UV-light on the $\mathrm{TiO}_{2}$ surface. Since more charge carriers will be generated when the catalyst surface interacts with more photons, the effective photon concentration is maximum in these samples (Figure 3). Therefore, the surface area increasing can lead to high photocatalytic activity and improved pollutant degradation efficiency.

However, the fitting process indicates that the relatively small changes in the rate constant 
possible reason for this behavior is the strong effect of the adsorption sites concentration on the photodegradation process.

\subsubsection{The effect of the modification of the photocatalyst on the degradation process}

The various studies clearly show the doping of semiconductors with non-metallic atoms, transition metals, and organic compounds play a vital role in their photocatalytic performance

The fitting results show the modification of the $\mathrm{TiO}_{2}$ and $\mathrm{ZnO}$ by the different materials, 504 such as the Fe, Ni, Ag, and RGO leads to the following beneficial effects in the photocatalyst: 505 (1) higher surface area; (2) the more effective trapping of the carriers; (3) the narrowing of the bandgap; (4) the increasing the concentration of water species and oxygen molecules on the photocatalyst surface. These results are in agreement with the experimental findings. The 508 incorporating the nickel into the zinc lattice produces more electron-hole pairs without altering 509 the crystal structure of the $\mathrm{ZnO}$ (Gnanamozhi et al. 2020).

The Fe and Ni dopant introduce the impurity states in the band gap of the $\mathrm{TiO}_{2}$ and $\mathrm{ZnO}$. Also, silver acts as an acceptor material to alter $\mathrm{ZnO}$ band gap energy. The results of the $\mathrm{X}$-ray (Peighambardoust et al. 2018). Besides, the coupling of the $\mathrm{TiO}_{2}$ with $\mathrm{RGO}$ decreases the bandgap energy ( $\mathrm{Li}$ et al. 2020). Therefore, the doping process in these semiconductors leads 
Chen et al. (Chen et al. 2015) observed that an appropriate amount of $\mathrm{Fe}^{3+}$ ions could act

as the reactive-centers for trapping of the charge carriers on the $\mathrm{TiO}_{2}$ surface. Reddy et al.

Therefore, the degradation rate increases by modifying the $\mathrm{TiO}_{2}$ and $\mathrm{ZnO}$ due to these

$$
\begin{aligned}
& \mathrm{Fe}^{3+} \text { orAg }+\mathrm{e}^{-} \rightarrow \mathrm{Fe}^{2+} \text { or } \mathrm{Ag}^{-} \\
& \mathrm{Fe}^{2+} \text { or } \mathrm{Ag}^{-}+\mathrm{O}_{2}(\text { ads }) \rightarrow \mathrm{Fe}^{2+} \text { or } \mathrm{Ag}^{-}-\mathrm{O}_{2} \text { (ads) } \\
& \mathrm{Fe}^{2+} \text { or } \mathrm{Ag}^{-}-\mathrm{O}_{2} \text { (ads) } \rightarrow \mathrm{Fe}^{3+} \text { or } \mathrm{Ag}+\mathrm{O}_{2}^{-\bullet}(\text { ads }) \\
& \mathrm{Fe}^{3+}, \mathrm{Ni}^{2+} \text { or } \mathrm{RGO}+\mathrm{O}_{2} \text { (ads) } \rightarrow \mathrm{Fe}^{3+}, \mathrm{Ni}^{2+} \text { or } \mathrm{RGO}-\mathrm{O}_{2} \text { (ads) } \\
& \mathrm{Fe}^{3+}, \mathrm{Ni}^{2+} \text { or } \mathrm{RGO}-\mathrm{O}_{2}(\text { ads })+\mathrm{e}^{-} \rightarrow \mathrm{Fe}^{2+}, \mathrm{Ni}^{+} \text {or } \mathrm{RGO}^{-}-\mathrm{O}_{2} \text { (ads) } \\
& \mathrm{Fe}^{2+}, \mathrm{Ni}^{+} \text {or } \mathrm{RGO}^{-}-\mathrm{O}_{2} \text { (ads) } \rightarrow \mathrm{Fe}^{3+}, \mathrm{Ni}^{2+} \text { or } \mathrm{RGO}+\mathrm{O}_{2}^{-\bullet} \text { (ads) } \\
& \mathrm{Fe}^{3+}, \mathrm{Ni}^{2+} \text { or } \mathrm{Ag}+\text { water species }\left(\mathrm{OH}^{-}(\mathrm{ads})\right) \\
& \rightarrow \mathrm{Fe}^{3+}, \mathrm{Ni}^{2+} \text { or } \mathrm{Ag}-\mathrm{OH}^{-} \text {(ads) }
\end{aligned}
$$




$$
\begin{aligned}
& \mathrm{Fe}^{3+}, \mathrm{Ni}^{2+} \text { or } \mathrm{Ag}-\mathrm{OH}^{-}(\text {ads })+\mathrm{h}^{+} \rightarrow \mathrm{Fe}^{3+}, \mathrm{Ni}^{2+} \text { or } \mathrm{Ag}-\mathrm{OH}^{\bullet} \text { (ads) } \\
& \mathrm{Fe}^{3+}, \mathrm{Ni}^{2+} \text { or } \mathrm{Ag}-\mathrm{OH}^{\bullet}(\text { ads }) \rightarrow \mathrm{Fe}^{3+}, \mathrm{Ni}^{2+} \text { or } \mathrm{Ag}+\mathrm{OH}^{\bullet} \text { (ads) }
\end{aligned}
$$

Based on these pathways, the concentration of the reactive centers for the studied systems are plotted in Figure 3. This figure indicates the effective concentration of reactive-centers in 3 wt. $\%$ Fe-doped $\mathrm{TiO}_{2}, 3$ wt. $\%$ Ni-doped $\mathrm{ZnO}, \mathrm{N}$-doped $\mathrm{TiO}_{2} / \mathrm{RGO}$ is higher than that of the other samples of their groups. The experimental and fitted results show that the increase of the photocatalytic efficiency of these samples can be attributed to the modification effect of the semiconductors.

\subsubsection{The reactions of the charge carriers (the trapping process)}

The third part of the proposed mechanism is a set of reactions in which the photogenerated electrons and holes. Therefore, they can play a more helpful role in the pollutant destruction

Reactive centers such as $\mathrm{RC} 1, \mathrm{RC} 2, \mathrm{RC} 3, \mathrm{RC} 4, \mathrm{RC} 5$, and $\mathrm{RC} 6$ play a prominent role in electron-hole pairs. The second type of the centers in bulk or on the surface can trap the charge carriers as follows:

$$
\begin{aligned}
& e^{-}+\mathrm{S} 1_{\text {trap }} \rightarrow \mathrm{e}_{\text {trap }} \\
& h^{+}+\mathrm{S} 2_{\text {trap }} \rightarrow \mathrm{h}_{\text {trap }}
\end{aligned}
$$

As shown in Table 4, the fitting results showed the rate constant for the Eq. (18) is slightly 
the first type of the effective reactive-centers has more significant effect on the conformity of the simulated results and experimental data. This result can be ascribed to the higher power of hydroxyl radicals generated by the valance band holes.

Water species are a crucial factor in forming some reactive-centers on the surface of the 559 $\mathrm{TiO}_{2}$ and $\mathrm{ZnO}$. In the proposed approach, water is adsorbed on the $\mathrm{TiO}_{2}$ surface in two forms, 560 i.e., the dissociative and the molecular. In molecular adsorption, the oxygen atom 561 electrostatically interacts with a $\mathrm{Ti}_{5 \mathrm{c}}$ site, and the hydrogens form the $\mathrm{H}$ bonds with two surface 562 $\mathrm{O}_{2 \mathrm{c}}$ sites on the next ridge. The formation of the hydrogen bonds between water molecules and 563 the $\mathrm{TiO}_{2}$ surface expands a strong network of high-ordered configurations (Mattioli et al. 2008). 564 In dissociative adsorption, the hydroxyl group bonds to a $\mathrm{Ti}_{5 \mathrm{c}}$ atom, and hydrogen ion bonds 565 to an $\mathrm{O}_{2 \mathrm{c}}$ atom. Therefore, two distinct hydroxyl groups can arise from the water dissociation 566 on the $\mathrm{TiO}_{2}$ surface, i.e., terminal and bridging hydroxyl species (Patrick \&Giustino 2014, 567 Wahab et al. 2008). Because the 5-fold coordinated Ti atoms act as Lewis acid sites able to 568 form powerful bonds with electron pairs of water molecules, and 2-fold coordinated oxygen 569 atoms act as Lewis base sites able to share a pair of the electrons with empty orbitals. Walle et 570 al. (Walle et al. 2011) showed that the amount of molecular and dissociated species of the 571 adsorbed water on the surface are comparable. Dissociative adsorption of water molecules can 572 produce hydroxyl groups and protons bonded to the $\mathrm{TiO}_{2}$ surface. The hydrogen and hydroxyl 573 ions of the aqueous solution are adsorbed on the $\mathrm{TiO}_{2}$ surface and create the reactive-centers 574 of the $\mathrm{RC} 1$. On the other hand, the interaction of water species and $\mathrm{Fe}^{3+}$ and $\mathrm{Ni}^{2+}$ ions leads to 575 the formation of the $\mathrm{RC} 2$ reactive-centers on the surface of the $\mathrm{Fe}$-doped $\mathrm{TiO}_{2}$ and $\mathrm{Ni}$-doped 576 $\mathrm{ZnO}$. It was reported (Carneiro et al. 2011) that the iron doping into the $\mathrm{TiO}_{2}$ lattice leads to 577 more surface hydroxylation.

In the past decades, the water interaction with the $\mathrm{ZnO}$ surface has been studied using both 579 experimental and computational methods. Martins et al (Martins et al. 1996) investigated the 
adsorption of the $\mathrm{H}_{2} \mathrm{O}$ molecules on a $(\mathrm{ZnO})_{22}$ cluster by using some semi-empirical

procedures. Their results indicated the weak interaction of the hydrogen atom of water with the

oxygen atom of the $\mathrm{ZnO}$ surface leads to the formation of the $\mathrm{O}-\mathrm{H}$.... $\mathrm{O}$ band.

583

Kharche et al. (Kharche et al. 2014) analyzed the microscopic structure of the $\mathrm{ZnO}$ aqueous interfaces using the first-principles density functional theory. They concluded that protons of the dissociated water molecules interact with the oxygen anions of the $\mathrm{ZnO}$ surface, while the 586 hydroxide ions interact with $\mathrm{Zn}$ cations. The presence of hydroxyl groups is confirmed by the 587 FT-IR spectroscopy (Gnanamozhi et al. 2020). The interaction of $\mathrm{H}_{2} \mathrm{O}$ molecule with the oxygen-terminated polar surface of $\mathrm{ZnO}$ was investigated by Kunat et al (Kunat et al. 2003). 589 They suggested that two $\mathrm{OH}$-species are formed by the dissociation of water molecules at the 590 O-vacancy. Therefore, water is adsorbed on the $\mathrm{ZnO}$ surface in both physisorption and 591 chemisorption forms (Nagao 1971, Yue et al. 2018).

The FT-IR spectra exhibit the presence of $\mathrm{Zn}-\mathrm{O}-\mathrm{Ni}$ bonds for all the Ni-doped $\mathrm{ZnO}$ 593 samples (Mousavi et al. 2017). Water molecules and hydroxyl ions can interact with nickel 594 ions on the Ni-doped $\mathrm{ZnO}$ surface to form the reactive-centers of the RC2 (Assowe et al. 2012, 595 Cappus et al. 1993, Simion et al. 2017). According to the proposed approach, these reactive596 centers have a synergistic effect on the organic pollutant photodegradation. The concentrations 597 of the reactive- centers are considered as a function of the $\mathrm{pH}$ solution. At the isoelectric point, 598 the molecular form of water is effective in the formation of the reactive-centers due to the low 599 concentration of hydroxyl and hydrogen ions.

Since the report of the photocatalysis phenomena, many authors (Montoya et al. 2013, 601 Salvador 2007) confirmed that electrons and holes are trapped in bulk or on the surface of 602 photocatalyst. It has been debated whether the VB free holes are trapped by surface-adsorbed 603 water species, or by the surface oxygen ions (Liu et al. 2014). The analysis of the electronic 604 structure showed (Bahnemann et al. 1984) the HOMO levels of the adsorbed water on the rutile 
The formation of surface-adsorbed hydroxyls in the $\mathrm{A}-$ doped $\mathrm{M}_{\mathrm{x}} \mathrm{O}_{\mathrm{y}}$ photocatalyst can

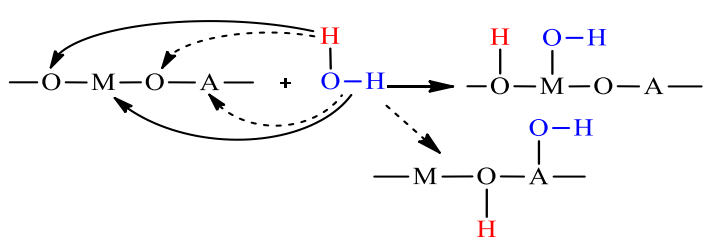

Photo-induced holes generated under UV illumination are simultaneously trapped with the 
According to the experimental conditions, it has been reported (Qian et al. 2019) the trapping timescale of the VB holes varies between picosecond and nanosecond. As shown in

Therefore, it is easy to understand the importance of water species and dopant level in the photocatalytic degradation of the pollutant using the proposed mechanism. As shown in Figure

Chen et al. (Chen et al. 2005) indicated the AO7 degradation is primarily initiates by photo- 
al. (Bahnemann et al. 1997) found a mechanism for the photocatalytic oxidation of

dichloroacetate and thiocyanate on the $\mathrm{TiO}_{2}$ (anatase). They stated the strongly-adsorbed

molecules react with the free VB holes, whereas the weakly-adsorbed species react with long-

The adjusted value of the rate constant (Table 4) shows the rate of this step is comparable with the trapping the holes in the reactive-centers of $\mathrm{RC} 1$ and $\mathrm{RC} 2$. In other words, the rate constant confirms the claim that direct attack of holes supports the pollutants destruction by

$\mathrm{RC} 1$ and RC2. Therefore, there are two distinct pathways for the degradation of organic because its proceeding depends on the adsorption reaction. One possible reason is that reactivecenters are more accessible than adsorbed molecules.

The photogenerated holes have a short life-time, which can attack and destroy the adsorbed 
On the other hand, excess electrons are usually available on the photocatalyst surface due

to various factors such as intrinsic defects, the other element doping into the $\mathrm{TiO}_{2}$ lattice, and adsorbed species on the photocatalyst surface.

Oxygen molecules can play an essential role in the formation of the reactive-centers. The ability of the charged oxygen molecules production is an influential factor in photoactivity. Wu 682 et al. (Wu et al. 2003) suggested two molecular and one dissociated adsorbed configurations 683 for the $\mathrm{O}_{2}$ adsorption on the $\mathrm{TiO}_{2}$ surface. In the most stable molecular configuration, the 684 oxygen molecule is adsorbed on the vacancy site, and binds to the two nearest Ti cations. In 685 the other molecular configuration, $\mathrm{O}_{2}$ molecule is located on top of a $\mathrm{Ti}_{5 \mathrm{c}}$ atom. The binding 686 energy of this configuration is $\sim 2 \mathrm{eV}$ smaller than the binding energy of the first configuration.

Due to the availability of adequate oxygen, our approach assumes the $\mathrm{O}_{2}$ molecules 688 primarily adsorb on the $\mathrm{A}-$ doped $\mathrm{M}_{\mathrm{x}} \mathrm{O}_{\mathrm{y}} / \mathrm{B}$ surface, leading to the formation of RC3, RC4, 689 and RC5. These reactive-centers trap the excess electrons. When the photogenerated holes 690 quickly migrate to the surface trapping centers, electrons are initially trapped in $\mathrm{Ti}^{4+}$ lattice 691 trapping states (Di Valentin et al. 2006). The photoexcited electrons in $\mathrm{Ti}^{3+}$ defect sites were 692 firmly confirmed by the electron paramagnetic resonance (EPR) technique (Hurum et al. 2003). 693 The transfer of one or more trapped electrons to the oxygen molecules leads to the formation 694 of adsorbed-surface oxygen, and consequently, the generation of the superoxide anion radicals. 695 It was reported (Fujishima et al. 2008) the trapped electrons react with oxygen molecules faster 696 than the free electrons.

Superoxide radicals $\left(\mathrm{O}_{2}^{--}\right)$enable to act as the effective species for destroying many toxic 698 organic pollutants (Carter et al. 2007, Ryu \&Choi 2004). Kuang et al (Kuang et al. 2016) found 699 that $40 \%$ of the total degradation of orange II and methylene blue dyes could be attributed to 700

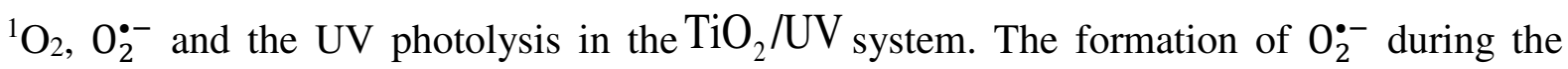


photocatalytic reactions was confirmed by several techniques (Jaeger \&Bard 1979, Nosaka et

al. 1997). The characteristic time for trapping of the charge carriers varies depending on the

experimental conditions from picosecond to nanosecond timescale (Friedmann et al. 2010).

704

Tamaki et al. (Tamaki et al. 2007) reported that the electrons and holes are trapped on the

surface of the anatase $\mathrm{TiO}_{2}$ at $\sim 200$ fs timescale.

Bahnemann et al. (Bahnemann et al. 1997) determined a rate constant of the reaction of the trapped electrons with oxygen molecules as $7.6 \times 10^{7} \mathrm{~L} \cdot \mathrm{mol}^{-1} \cdot \mathrm{s}^{-1}$. Gerischer (Gerischer 1995) 708 reported the rate constants for transfer of free and trapped electrons to oxygen molecules are 709 $4.5 \times 10^{7} \mathrm{~s}^{-1}$ and $4.5 \times 10^{3} \mathrm{~s}^{-1}$, respectively.

In our study, it is assumed the concentration of dissolved oxygen (DO) remains constant during the photocatalytic reaction. Pan et al. (Li et al. 2019) investigated the various properties of the $\mathrm{ZnO}$ nanoparticle as a gas sensor. They found that oxygen molecules are rapidly preadsorbed on the surface of the $\mathrm{ZnO}$ (001). Wang et al. (Li et al. 2005) studied the sensing 714 mechanism of the $\mathrm{ZnO}$ films by the transient photocurrent technique. Their results indicated 715 that $\mathrm{O}_{2}$ molecules are adsorbed on the surface of $\mathrm{ZnO}$ in both physisorption and chemisorption forms. When the $\mathrm{Ni}$-doped $\mathrm{ZnO}$ is exposed to oxygen, the reactive-centers of the $\mathrm{Ni}-\mathrm{O}_{2}$ are 717 formed by the reaction of the adsorbed oxygen molecules with nickel ions (Norton et al. 1977, 718 Qian et al. 2020).

In our provided mechanism, the photogenerated electrons are trapped by $\mathrm{Ti}^{4+}, \mathrm{Fe}^{3+}, \mathrm{Zn}^{2+}$, 720 and $\mathrm{Ni}^{2+}$ ions in the reactive-centers of $\mathrm{Ti}^{4+}-\mathrm{O}_{2}$ (ads), $\mathrm{Fe}^{3+}-\mathrm{O}_{2}$ (ads), $\mathrm{Zn}^{2+}-\mathrm{O}_{2}$ (ads), 721 $\mathrm{Ni}^{2+}-\mathrm{O}_{2}$ (ads), and $\mathrm{RGO}-\mathrm{O}_{2}$ (ads). Besides, silver is considered as a reactive-center, which can accept and transfer the CB electrons of the semiconductor. Some studies (Sengunthar et al. 2020, $\mathrm{Yu}$ et al. 2018) showed the higher photocatalytic efficiency of $\mathrm{RGO} / \mathrm{TiO}_{2}$ and $\mathrm{RGO} / \mathrm{ZnO}$ is attributed to RGO. It acts as (1) a charge separator, (2) a photosensitizer, and (3) a good 
adsorbent. The RGO sheets transfer the CB electrons to the adsorbed oxygen molecules on the nanocomposite surface to produce $\mathrm{O}_{2}^{\bullet-}$ radicals.

As shown in Figure 3c, the improvement of the photocatalytic efficiency of the N-doped $\mathrm{TiO}_{2} / \mathrm{RGO}$ sample can be attributed to the presence of RC5 reactive-centers, which can trap 729 the CB electrons. The fitting results show the rate constant of the trapping of photo-induced 730 electrons by the reactive-centers of the RC3, RC4, and RC5 is in the order of $10^{9}$. The values 731 of the rate constants are consistent with this strategy and to the timescale of the process of trapping the $\mathrm{CB}$ electrons on the $\mathrm{TiO}_{2}$ surface (Friedmann et al. 2010).

The results of our work show the fitting process is affected by changing the value of the rate constant for the reaction of the $\mathrm{CB}$ electrons with the reactive-centers of the RC3, RC4, 735 and RC5. Therefore, using the proposed mechanism, the role of the following two factors in 736 the pollutants photodegradation can be explained: (1) the synergistic effect of the $\mathrm{Fe}^{3+}, \mathrm{Ni}^{2+}$, 737 $\mathrm{RGO}$, and $\mathrm{Ag}^{+}$with $\mathrm{TiO}_{2}$ and $\mathrm{ZnO}$, and (2) the flow rate of the $\mathrm{O}_{2}$.

The proposed mechanism is in good agreement with the experimental results. Trapping 739 experiments showed that $\mathrm{OH}^{\bullet}$ and $\mathrm{O}_{2}^{\cdot-}$ in the system of the $\mathrm{Ag} / \mathrm{ZnO} / \mathrm{O}_{3} /$ Phenol plays a major 740 role in the degradation of pollutants, which is consistent with the EPR results (Peng et al. 2019). On the other hand, the radical quenching experiments clearly indicated that $\mathrm{O}_{2}^{\circ-}$ radicals have 742 an important role in the TC photodegradation under visible light illumination (Tang et al. 2018).

Hydrogen peroxide $\left(\mathrm{H}_{2} \mathrm{O}_{2}\right)$ is another important ROSs in photocatalytic systems. It is 745 produced from two pathways during the photocatalytic processes. Those are the two-hole 746 oxidation of $\mathrm{H}_{2} \mathrm{O}$ and the two-electron reduction of $\mathrm{O}_{2}$ (ads) (Hirakawa et al. 2001, Nosaka \&Nosaka 2017, Sahel et al. 2016), as follows:

$$
\begin{aligned}
& 2 \mathrm{H}_{2} \mathrm{O}+2 \mathrm{~h}^{+} \rightarrow \mathrm{H}_{2} \mathrm{O}_{2}+2 \mathrm{H}^{+} \\
& \mathrm{O}_{2}^{\bullet-}+\mathrm{e}^{-}+2 \mathrm{H}^{+} \rightarrow \mathrm{H}_{2} \mathrm{O}_{2}
\end{aligned}
$$


The reduction pathway seems to be dominant due to the low reactivity of superoxide radicals.

$\mathrm{Li}$ and Selloni ( $\mathrm{Li} \&$ Selloni 2013) found the generation of $\mathrm{O}_{2}^{--}$via the transfer of an electron

superoxide to produce an adsorbed $\mathrm{H}_{2} \mathrm{O}_{2}$ is nonadiabatic, and it has a barrier of $0.3 \mathrm{eV}$ at the suspension of the $\mathrm{TiO}_{2}$ and $\mathrm{ZnO}$ under UV illumination (Mrowetz \&Selli 2006, Nosaka et al. 754 1997). It can be formed by the reaction of the electrons with superoxide radicals in the presence

$$
\mathrm{O}_{2}^{-\bullet}(\text { ads })+\mathrm{e}^{-}+2 \mathrm{H}^{+} \rightarrow \mathrm{H}_{2} \mathrm{O}_{2} \text { (ads) }
$$

It was reported (Nosaka \&Nosaka 2017) the quantum yield of the $\mathrm{H}_{2} \mathrm{O}_{2}$ generation is in 757 the order of $10^{-7}$ for the $\mathrm{TiO}_{2}$ powder, and in the order of $10^{-3}$ for the anatase $\mathrm{TiO}_{2}$ films. 758 Although the rate constant of this reaction is high, the fitting results show that this reaction has 759 little effect on the fitting curve. The reason may be as follows: (1) the proceeding of this 760 reaction depends on the presence of three species; (2) the concentration of hydrogen ions is low in the non-acidic solution.

The rate constant for the reaction of the aqueous electrons with $\mathrm{H}_{2} \mathrm{O}_{2}$ is in the order of $10^{10}$ 763 $\mathrm{M}^{-1} \cdot \mathrm{s}^{-1}$ (Gierer et al. 1994). This reaction is thermodynamically favorable $\left(\Delta \mathrm{E}^{0}=+0.73 \mathrm{~V}\right.$ at 764 pH 7) (Nosaka \&Nosaka 2017). The fitting results show the adjusted value of the rate constant 765 for the electron reaction with $\mathrm{H}_{2} \mathrm{O}_{2}$ is in the order of $10^{9}$. This result is consistent with the 766 trapping process of the $\mathrm{CB}$ electrons on the $\mathrm{TiO}_{2}$ surface. Therefore, the reaction of electrons with $\mathrm{H}_{2} \mathrm{O}_{2}$ has a significant effect on degradation of organic pollutant. As a result, the effect of 768 $\mathrm{H}_{2} \mathrm{O}_{2}$ on the degradation process in photocatalytic systems can be investigated with these explanations. 
The sixth part of the general mechanism is the recombination of the charge carriers. In our approach, the degradation of the organic pollutants is prevented by both recombinations of the free and the trapped electron-hole pairs. The trapping of the charge carriers not only prevents the recombination process but also increased the carriers lifetime. As seen in Table 4, the value of the rate constant is in the order of $10^{9}$ for this step. In this work, the effect of the recombination of the charge carriers on the fitting process was investigated by changing the value of the rate constant. The fitting results show that the recombination of $\mathrm{e}^{-} / \mathrm{h}^{+}$pairs has a determining role in the degradation of the organic pollutant. The recombination of the charge 780 carriers is an important step of the photodegradation process that occurs in a femtosecond timescale. The quantum yields of the most photocatalytic reactions are less than $10 \%$, and it can be due to the recombination process. After a certain time, the charge carriers are 783 recombined to produce light and heat. The recombination of the charge carriers is one of the 784 most important factors in the fabrication of photocatalysts and the design of the photoreactors 785 (Li \&Li 2002, Visan et al. 2019, Wang et al. 2010).

The adjusted value of the rate constant for the recombination of the charge carriers shows that this step has a significant effect on the degradation process of organic pollutants. Besides, 788 the fitting results indicate the following findings: (1) the free charge carriers recombine faster 789 than the charge carriers trapped by the $\mathrm{TiO}_{2}$ surface; (2) the value of $R^{2}$ changes significantly 790 by changing the value of the rate constant for the trapping of the $\mathrm{CB}$ electrons by the semieffective centers; (3) the fitting process is strongly influenced by the recombination of the charge carriers trapped in the reactive-centers.

Figure 3 shows that the concentration of the semi-effective centers is highest in the 794 following samples: $3 \%$ wt. Fe-doped $\mathrm{TiO}_{2}, \mathrm{pH}=3,3 \%$ wt. Ni-doped $\mathrm{ZnO}, \mathrm{N}$-doped $\mathrm{TiO}_{2} / \mathrm{RGO}$, 795 and $\mathrm{Ag}$-doped $\mathrm{ZnO} / \mathrm{O}_{3}$. The fitting results are in agreement with the experimental results. Using 796 the proposed approach, a deeper understanding of the recombination process is obtained, and 
the obtained results are in agreement with the previous studies (Krýsa et al. 2006, Qian et al.

\subsubsection{Inactivation reactive-centers}

A prominent feature of the proposed mechanism is that hydroxyl radicals are consumed by the inactivation of the reactive-centers (Barka et al. 2010, Daneshvar et al. 2004, Dutta et al. 2009).

$$
\begin{aligned}
& \mathrm{TiO}^{\bullet} \mathrm{H}+\mathrm{TiO}^{\bullet} \mathrm{H} \rightarrow \mathrm{H}_{2} \mathrm{O}_{2} \text { (ads) } \\
& \mathrm{TiO}^{\bullet} \mathrm{H}+\mathrm{OH}^{-} \rightarrow \mathrm{H}_{2} \mathrm{O}_{2} \text { (ads) }+\mathrm{e}^{-}
\end{aligned}
$$

Daneshvar et al. (Daneshvar et al. 2004) and Dutta et al. (Dutta et al. 2009) assumed the hydroxyl radicals produced in the photocatalytic reaction could be consumed by the inactivation species. They suggested that inactivation of the hydroxyl radicals with inactive-

On the other hand, some inactivated $\mathrm{OH}^{\bullet}$ radicals may be reactivated by the participation

$$
\mathrm{Ti}^{\mathrm{IV}}+\mathrm{e}^{-}+\mathrm{H}_{2} \mathrm{O} \rightarrow \mathrm{Ti}^{\mathrm{III}} \mathrm{OH}_{2}
$$




$$
\mathrm{Ti}^{\mathrm{III}} \mathrm{OH}_{2}+\mathrm{H}_{2} \mathrm{O}_{2} \text { (ads) } \rightarrow \mathrm{TiO}^{\bullet} \mathrm{H}+\mathrm{OH}^{-}+\mathrm{Ti}^{\mathrm{IV}} \mathrm{OH}_{2}
$$

In this work, the effect of the re-activation step on the degradation of the organic pollutant was investigated by changing the values of the rate constants. The results indicated that the reactivation process in the studied systems is much less important than the generation of hydroxyl radicals or the inactivation reaction. For this reason, the reactivation steps were omitted in the final mechanism.

\subsubsection{Comparison of the pollutants photodegradation caused by different light sources}

This approach can be used to investigate the photodegradation mechanism of the organic

pollutants by photocatalysts with the general formula A-doped $\mathrm{M}_{\mathrm{x}} \mathrm{O}_{\mathrm{y}}$ under different irradiation

sources. In this work, the $\mathrm{AO} 7$ photodegradation on the $2 \mathrm{wt} . \%$ Fe-doped $\mathrm{TiO}_{2}$ surface induced

by different light sources was simulated. The curves of the AO7 concentration versus time for

these samples is plotted in Figure (5). As can be seen in this figure, there is good conformity between the results of the simulation and the experimental data. The adjusted values of the rate constants of the first step for the irradiation sources of the UV-, solar-, and visible-light are: $1.47 \times 10^{-3}, 7.33 \times 10^{-4}$, and $4.90 \times 10^{-4} \mathrm{M}^{-1} \cdot \mathrm{min}^{-1}$. The rate constant of the other steps is the same as the values given in Table (2) for the Fe-doped $\mathrm{TiO}_{2}$ system. These results show the degradation efficiency of the UV-light is greater than that of the solar-light and visible-light. $\mathrm{TiO}_{2} /$ visible-light/AO7 system is lower than other samples. The reason can be attributed to the lower power of visible-light photons. This decreases the effective concentration of the charge carriers and thus the rate of the AO7 degradation.

We predict the proposed approach can also be used to investigate the mechanism and kinetics of photocatalytic reactions using other photocatalysts such as sulfides. However, it should be examined in another study. 


\section{Conclusion}

In this study, a new approach and a general mechanism are provided to investigate the kinetics

of the degradation of the organic pollutants by the photocatalysts under UV/Vis light

irradiation. This approach was examined to find a suitable mechanism for the photodegradation

of the four different empirical systems of acid orange 7 on $\mathrm{Fe}^{3+}$-doped $\mathrm{TiO}_{2}$ nanocatalysts,

ozonation of phenol on $\mathrm{Ag} / \mathrm{ZnO}$ nanocomposites, tetracycline hydrochloride on $\mathrm{N}$-doped

$\mathrm{TiO}_{2} /$ reduced graphene oxide, and congo $\mathrm{Red}$ on $\mathrm{Ni}$-doped $\mathrm{ZnO}$. The production of the

effective reactive-centers and the trapping of the charge carriers are two main strategies used

in the proposed mechanism. This mechanism describes the experimental data well, and it can

be used to predict the behavior of the photocatalytic systems at different conditions. The fitting

results showed the excellent conformities between the calculated and experimental data at

Two methods were used to estimate the parameters: the hybrid manual-automatic method

and the optimization-based techniques. The first method can be performed in two steps to

obtain good agreement between the experimental data and the fitting results: (1) manual

adjusting the system parameters, and (2) the optimization by the fminsearch function. The

fitting results show the hybrid manual-automatic method leads to reliable values than

(1) the rate constant of electron-hole generation step in the proposed mechanism is in the order of $10^{-3}$ for UV-light and $10^{-1}$ for visible light illumination. Therefore, a small fraction of the charge carriers can lead to the degradation of the organic pollutants;

(2) the photocatalyst surface is composed of the different reactive-centers in contact to the water species and the other materials. Depending on the reaction conditions, a certain number of these 
increases the surface area, the effective reactive-centers, and the trapped $\mathrm{e}^{-} / \mathrm{h}^{+}$pairs, and thus,

(3) the photodegradation efficiency is highest when the effective concentration of the reactivecenters and the effective concentration of photons are maximum. Therefore, the optimum for different conditions;

(4) the hydroxyl radicals and superoxide radicals are mainly responsible for the degradation of the organic pollutants;

The proposed mechanism in this work can be utilized to construct efficient photocatalysts, to study the kinetics of the organic pollutants photodegradation on the surface, and to optimize them.

\section{Availability of data and materials}

The datasets used and/or analyzed during the current study are available from the

All data generated or analyzed during this study are included in this published article [and its

Not applicable.

Not applicable. 


\section{Acknowledgement}

The authors are grateful to University of Kashan for supporting this work by Grant No. 900 $(1073182 / 3)$.

$\bigotimes$ The authors declare that they have no known competing financial interests or personal relationships that could have appeared to influence the work reported in this paper.

囚The authors declare the following financial interests/personal relationships which may be

\section{References:}

Al-Ekabi H, Serpone N, Pelizzetti E, Minero C, Fox MA, Draper RB (1989): Kinetic studies in heterogeneous photocatalysis. 2. Titania-mediated degradation of 4-chlorophenol alone and in a three-component mixture of 4-chlorophenol, 2, 4-dichlorophenol, and $-5,4$, 2trichlorophenol in air-equilibrated aqueous media. Langmuir 5: 250-255

Al-Kdasi A, Idris A, Saed K, Guan CT (2004): Treatment of textile wastewater by advanced oxidation processes - a review. Global nest: the Int. J 6: 222-230

Al-Rasheed RA (2005): Water treatment by heterogeneous photocatalysis an overview, 4th SWCC acquired Experience Symposium held in Jeddah, pp. 1-14 adsorption and photocatalytic degradation efficiency of different catalysts on removal of methylene blue. Asian J. Chem. 26: 8445 for water purification and recovery. Catal. Today 53: 51-59 molecular dynamics simulation study of corrosion of nickel, Defect and Diffusion $\quad 926$ Forum. Trans Tech Publ, pp. 139-145 927

Bahnemann D, Henglein A, Lilie J, Spanhel L (1984): Flash photolysis observation of the 928 absorption spectra of trapped positive holes and electrons in colloidal titanium $\quad 929$ dioxide. The Journal of Physical Chemistry 88: 709-711 
Bahnemann DW, Hilgendorff M, Memming R (1997): Charge carrier dynamics at $\mathrm{TiO}_{2}$ particles: reactivity of free and trapped holes. The Journal of Physical Chemistry B 101: 4265-4275

Barka N, Qourzal S, Assabbane A, Ait-Ichou Y (2010): Kinetic modeling of the photocatalytic degradation of methyl orange by supported $\mathrm{TiO}_{2}$. Journal of Environmental Science and Engineering 4: 1-5

Bashiri H, Jalali HM, Rasa H (2014): Determination of intracellular levels of reactive oxygen species using the 2, 7-dichlorofluorescein diacetate assay by kinetic Monte Carlo simulation. Progress in Reaction Kinetics and Mechanism 39: 281-291

Bashiri H, Mohamadi S (2016): Hydrogen sulfide decomposition on Ni surface: A kinetic Monte Carlo study. Applied Catalysis A: General 509: 105-110

Bashiri H, Pourbeiram N (2016): Biodiesel production through transesterification of soybean oil: A kinetic Monte Carlo study. J. Mol. Liq. 223: 10-15

Berberidou C, Kitsiou V, Karahanidou S, Lambropoulou DA, Kouras A, Kosma CI, Albanis TA, Poulios I (2016): Photocatalytic degradation of the herbicide clopyralid: kinetics, degradation pathways and ecotoxicity evaluation. Journal of Chemical Technology \& Biotechnology 91: 2510-2518

Cappus D, Xu C, Ehrlich D, Dillmann B, Ventrice Jr C, Al Shamery K, Kuhlenbeck H, Freund H-J (1993): Hydroxyl groups on oxide surfaces: $\mathrm{NiO}$ (100), $\mathrm{NiO}$ (111) and $\mathrm{Cr}_{2} \mathrm{O}_{3}$ (111). Chem. Phys. 533-546:177

Carneiro JT, Savenije TJ, Moulijn JA, Mul G (2011): How phase composition influences optoelectronic and photocatalytic properties of $\mathrm{TiO}_{2}$. The Journal of Physical Chemistry C 115: 2211-2217

Carraway ER, Hoffman AJ, Hoffmann MR (1994): Photocatalytic oxidation of organic acids on quantum-sized semiconductor colloids. Environ. Sci. Technol. 28: 786-793

Carter E, Carley AF, Murphy DM (2007): Evidence for $\mathrm{O}_{2}$-radical stabilization at surface oxygen vacancies on polycrystalline $\mathrm{TiO}_{2}$. The Journal of Physical Chemistry C 111: 10630-10638

Chakrabarti S, Dutta BK (2004): Photocatalytic degradation of model textile dyes in wastewater using $\mathrm{ZnO}$ as semiconductor catalyst. J. Hazard. Mater. 112: 269-278

Chen C-C, Hu S-H, Fu Y-P (2015): Effects of surface hydroxyl group density on the photocatalytic activity of $\mathrm{Fe}^{3+}$-doped $\mathrm{TiO}_{2}$. J. Alloys Compd. 632: 326-334 962

Chen Y, Yang S, Wang K, Lou L (2005): Role of primary active species and $\mathrm{TiO}_{2}$ surface 963 characteristic in UV-illuminated photodegradation of Acid Orange 7 .Journal of 964 Photochemistry and Photobiology A: Chemistry 172: 47-54

Chen Y, Liu K (2016): Preparation and characterization of nitrogen-doped $\mathrm{TiO}_{2} /$ diatomite integrated photocatalytic pellet for the adsorption-degradation of tetracycline hydrochloride using visible light. Chem. Eng. J. 302: 682-696

Daneshvar N, Rabbani M, Modirshahla N, Behnajady M (2004): Kinetic modeling of photocatalytic degradation of Acid Red 27 in $\mathrm{UV} / \mathrm{TiO}_{2}$ process. Journal of Photochemistry and Photobiology A: Chemistry 168: 39-45

Devi LG, Nithya P, Abraham C, Kavitha R (2017): Influence of surface metallic silver $\quad 972$ deposit and surface fluorination on the photocatalytic activity of rutile $\mathrm{TiO}_{2}$ for the $\quad 973$ degradation of crystal violet a cationic dye under UV light irradiation. Materials 974 Today Communications 10: 1-13

Di Valentin C, Pacchioni G, Selloni A (2006): Electronic structure of defect states in hydroxylated and reduced rutile $\mathrm{TiO}_{2}$ (110) surfaces. Phys. Rev. Lett. 97: 166803 
Dror I, Fink L, Weiner L, Berkowitz B (2020): Elucidating the catalytic degradation of enrofloxacin by copper oxide nanoparticles through the identification of the reactive oxygen species. Chemosphere 258: 127266

983

Dutta S, Parsons SA, Bhattacharjee C, Jarvis P, Datta S, Bandyopadhyay S (2009): Kinetic study of adsorption and photo-decolorization of Reactive Red 198 on $\mathrm{TiO}_{2}$ surface. Chem. Eng. J. 15674-679:5

985

986

El Mragui A, Logvina Y, Pinto da Silva L, Zegaoui O, Esteves da Silva JC (2019): Synthesis

987 of $\mathrm{Fe}$-and $\mathrm{Co}$-doped $\mathrm{TiO}_{2}$ with improved photocatalytic activity under visible irradiation toward carbamazepine degradation. Materials 12: 3874

988

989

Emeline AV, Ryabchuk V, Serpone N (2000): Factors affecting the efficiency of a

990 photocatalyzed process in aqueous metal-oxide dispersions: prospect of distinguishing between two kinetic models. Journal of Photochemistry and Photobiology A:

992 Chemistry 133: 89-97

993

Forsythe GE (1977): Computer methods for mathematical computations. Prentice-Hall series 994 in automatic computation 259

Friedmann D, Mendive C, Bahnemann D (2010): $\mathrm{TiO}_{2}$ for water treatment: parameters affecting the kinetics and mechanisms of photocatalysis. Applied Catalysis B: Environmental 99: 398-406

995

996

997

998

Fujishima A, Zhang X, Tryk DA (2008): $\mathrm{TiO}_{2}$ photocatalysis and related surface phenomena. Surf. Sci. Rep. 63: 515-582

999

1000

Galindo C, Jacques P, Kalt A (2000): Photodegradation of the aminoazobenzene acid orange 1001 52 by three advanced oxidation processes: $\mathrm{UV} / \mathrm{H}_{2} \mathrm{O}_{2}, \mathrm{UV} / \mathrm{TiO}_{2}$ and $\mathrm{VIS} / \mathrm{TiO}_{2}$ : 1002 comparative mechanistic and kinetic investigations. Journal of Photochemistry and 1003 Photobiology A: Chemistry 130: 35-47

1003
1004

Garrafa-Gálvez HE, Alvarado-Beltrán CG, Almaral-Sánchez JL, Hurtado-Macías A, Garzon-

1005 Fontecha AM, Luque PA, Castro-Beltrán A (2019): Graphene role in improved solar

1006 photocatalytic performance of $\mathrm{TiO}_{2}$-RGO nanocomposite. Chem. Phys. 521: 35-43

1007

Gerischer H (1995): Photocatalysis in aqueous solution with small $\mathrm{TiO}_{2}$ particles and the dependence of the quantum yield on particle size and light intensity. Electrochim. Acta 40: 1277-1281

1008

1009

1010

Ghatak HR (2014): Advanced oxidation processes for the treatment of biorecalcitrant 1011 organics in wastewater. Crit. Rev. Environ. Sci. Technol. 44: 1167-1219 1012

Gierer J, Yang E, Reitberger T (1994): On the Significance of the Superoxide Radical in 1013 Oxidative Delignification, Studied with 4-t-Butylsyringol and 4-t-Butylguaiacol. Part 1014 I. The Mechanism of Aromatic Ring Opening. Holzforschung-International Journal of 1015 the Biology, Chemistry, Physics and Technology of Wood 48: 405-414 1016

Gnanamozhi P, Renganathan V, Chen S-M, Pandiyan V, Arockiaraj MA, Alharbi NS,

1017 Kadaikunnan S, Khaled JM, Alanzi KF (2020): Influence of Nickel concentration on the photocatalytic dye degradation (methylene blue and reactive red 120) and

1018 antibacterial activity of $\mathrm{ZnO}$ nanoparticles. Ceram. Int. 46: 18322-18330

1019

1020

$\begin{array}{rr}\text { Gomez-Ruiz B, Ribao P, Diban N, Rivero MJ, Ortiz I, Urtiaga A (2018): Photocatalytic } & 1021 \\ \text { degradation and mineralization of perfluorooctanoic acid (PFOA) using a composite } & 1022\end{array}$ $\mathrm{TiO}_{2}-$ rGO catalyst. J. Hazard. Mater. 344: 950-957

1023

1024 $\begin{array}{ll}\text { in water over modified titanium dioxide. Applied Catalysis B: Environmental 36: 45- } & 1025 \\ 51 & 1026\end{array}$

Guo MY, Ng AMC, Liu F, Djurišić AB, Chan WK (2011): Photocatalytic activity of metal 1027 oxides - the role of holes and OH radicals. Applied Catalysis B: Environmental 107: 1028 $150-157$ 
Gupta VK, Jain R, Mittal A, Saleh TA, Nayak A, Agarwal S, Sikarwar S (2012): Photocatalytic degradation of toxic dye amaranth on $\mathrm{TiO}_{2} / \mathrm{UV}$ in aqueous suspensions. Materials Science and Engineering: C 32: 12-17

Han F, Kambala V, Dharmarajan R, Liu Y, Naidu R (2018): Photocatalytic degradation of azo dye acid orange 7 using different light sources over $\mathrm{Fe}^{3+}$-doped $\mathrm{TiO}_{2}$ nanocatalysts. Environmental Technology \& Innovation 12: 27-42

Haque M, Khan A, Umar K, Mir NA, Muneer M, Harada T, Matsumura M (2013): Synthesis, characterization and photocatalytic activity of visible light induced $\mathrm{Ni}$-doped $\mathrm{TiO}_{2}$. Energy and Environment Focus 2: 73-78

Hirakawa T, Kominami H, Ohtani B, Nosaka Y (2001): Mechanism of photocatalytic production of active oxygens on highly crystalline $\mathrm{TiO}_{2}$ particles by means of chemiluminescent probing and ESR spectroscopy. The Journal of Physical Chemistry B 105: 6993-6999

Hitam C, Jalil A (2020): A review on exploration of $\mathrm{Fe}_{2} \mathrm{O}_{3}$ photocatalyst towards degradation of dyes and organic contaminants. Journal of Environmental Management 258: 110050 morphological and optical properties of $\mathrm{TiO}_{2}$ based photoanode of dye-sensitized solar cell. Materials Science-Poland 93-101:36 Zhou Y (2013): Enhanced photocatalytic degradation of dyes by $\mathrm{TiO}_{2}$ nanobelts with hierarchical structures. Journal of Photochemistry and Photobiology A: Chemistry $7-15: 256$

1053

Huang Y, Wang H, Huang K, Huang D, Yin S, Guo Q (2020): Degradation kinetics and mechanism of 3-Chlorobenzoic acid in anoxic water environment using graphene/ $/ \mathrm{TiO}_{2}$ as photocatalyst. Environ. Technol. 41: 2165-2179

1054

1055

1056

Hurum DC, Agrios AG, Gray KA, Rajh T, Thurnauer MC (2003): Explaining the enhanced photocatalytic activity of Degussa P25 mixed-phase $\mathrm{TiO}_{2}$ using EPR. The Journal of Physical Chemistry B 107: 4545-4549

Ibhadon AO, Fitzpatrick P (2013): Heterogeneous photocatalysis: recent advances and applications. Catalysts 3: 189-218

1061

Jaeger CD, Bard AJ (1979): Spin trapping and electron spin resonance detection of radical

1062 intermediates in the photodecomposition of water at titanium dioxide particulate systems. Journal of Physical Chemistry 83: 3146-3152

1063

1064

Kaur P, Sud D (2012): Photocatalytic degradation of quinalphos in aqueous $\mathrm{TiO}_{2}$ suspension:

1065 Reaction pathway and identification of intermediates by GC/MS. J. Mol. Catal. A: Chem. 365: 32-38

Kazeminezhad I, Sadollahkhani A (2016): Influence of pH on the photocatalytic activity of $\mathrm{ZnO}$ nanoparticles. Journal of Materials Science: Materials in Electronics 27: 42064215

Khalifa M, Bidaisee S (2018): The importance of clean water. Sch J Appl Sci Res 1: 17-20 as efficient solar light-driven photocatalysts for degradation of Congo red dye. Inorg. Chem. Commun. 72: 33-41 and electronic properties of aqueous interfaces of $\mathrm{GaN}, \mathrm{ZnO}$, and a $\mathrm{GaN} / \mathrm{ZnO}$ alloy. 
Roles of adsorption processes and mechanistic complexity. Applied Catalysis B:

Kuang L, Zhao Y, Zhang W, Ge S (2016): Roles of Reactive Oxygen Species and Holes in 1082 the Photodegradation of Cationic and Anionic Dyes by TiO 2 under UV Irradiation. 1083 Journal of Environmental Engineering 142: 04015065

Kumar S, Singh V, Tanwar A (2016): Structural, morphological, optical and photocatalytic properties of Ag-doped $\mathrm{ZnO}$ nanoparticles. Journal of Materials Science: Materials in Electronics 27: 2166-2173

1086

Kunat M, Girol SG, Burghaus U, Wöll C (2003): The interaction of water with the oxygenterminated, polar surface of $\mathrm{ZnO}$. The Journal of Physical Chemistry B 107: 1435014356

1090

Lai CW, Juan JC, Ko WB, Bee Abd Hamid S (2014): An overview: recent development of 1091 titanium oxide nanotubes as photocatalyst for dye degradation. International Journal 1092 of Photoenergy 2014

Lau W-J, Ismail AF (2009): Polymeric nanofiltration membranes for textile dye wastewater treatment: preparation, performance evaluation, transport modelling, and fouling control-a review. Desalination 245: 321-348

Lerkkasemsan N 2010: Mechanistic Modeling of Biodiesel Production via Heterogeneous Catalysis, Virginia Tech

Li C, Zhou H, Yang S, Wei L, Han Z, Zhang Y, Pan H (2019): Preadsorption of $\mathrm{O}_{2}$ on the exposed (001) facets of $\mathrm{ZnO}$ nanostructures for enhanced sensing of gaseous acetone. ACS Applied Nano Materials 2: 6144-6151

1093

1094

1095

1096

1097

1098

1099

1100

1101

Li F, Li X (2002): The enhancement of photodegradation efficiency using Pt- $\mathrm{TiO}_{2}$ catalyst. 1102 Chemosphere 48: 1103-1111

1103

1104

Li Q, Gao T, Wang Y, Wang T (2005): Adsorption and desorption of oxygen probed from $\mathrm{ZnO}$ nanowire films by photocurrent measurements. Appl. Phys. Lett. 86: 123117

1105

1106

Li R, Song X, Huang Y, Fang Y, Jia M, Ma W (2016): Visible-light photocatalytic degradation of azo dyes in water by $\mathrm{Ag}_{3} \mathrm{PO}_{4}$ : An unusual dependency between adsorption and the degradation rate on $\mathrm{pH}$ value. J. Mol. Catal. A: Chem. 421: 57-65

Li S, Chen H, Wang X, Dong X, Huang Y, Guo D (2020): Catalytic degradation of clothianidin with graphene/ $\mathrm{TiO}_{2}$ using a dielectric barrier discharge (DBD) plasma system. Environmental Science and Pollution Research 27: 29599-29611

Li Y-F, Selloni A (2013): Theoretical study of interfacial electron transfer from reduced anatase $\mathrm{TiO}_{2}$ (101) to adsorbed $\mathrm{O}_{2}$. Journal of the American Chemical Society 135: 9195-9199

Li Y-F, Zhang W-P, Li X, Yu Y (2014): $\mathrm{TiO}_{2}$ nanoparticles with high ability for selective adsorption and photodegradation of textile dyes under visible light by feasible preparation. J. Phys. Chem. Solids 75: 86-93

Liang C-Z, Sun S-P, Li F-Y, Ong Y-K, Chung T-S (2014): Treatment of highly concentrated wastewater containing multiple synthetic dyes by a combined process of coagulation/flocculation and nanofiltration. J. Membr. Sci. 469: 306-315

Liu B, Zhao X, Terashima C, Fujishima A, Nakata K (2014): Thermodynamic and kinetic analysis of heterogeneous photocatalysis for semiconductor systems. Physical Chemistry Chemical Physics 16: 8751-8760

Liu G, Li X, Zhao J, Horikoshi S, Hidaka H (2000) :Photooxidation mechanism of dye theoretical examination. J. Mol. Catal. A: Chem. 153: 221-229 
Mao Y, Schoeneich C, Asmus KD (1991): Identification of organic acids and other intermediates in oxidative degradation of chlorinated ethanes on titania surfaces en route to mineralization: a combined photocatalytic and radiation chemical study. The Journal of Physical Chemistry 95: 10080-10089

Martins JB, Andrés J, Longo E, Taft C (1996): $\mathrm{H}_{2} \mathrm{O}$ and $\mathrm{H}_{2}$ interaction with $\mathrm{ZnO}$ surfaces: a MNDO, AM1, and PM3 theoretical study with large cluster models. International journal of quantum chemistry $57: 861-870$

Mattioli G, Filippone F, Caminiti R, Bonapasta AA (2008): Short hydrogen bonds at the water/ $\mathrm{TiO}_{2}$ (anatase) interface. The Journal of Physical Chemistry C 112: 1357913586

Minero C, Maurino V, Vione D (2013): Photocatalytic mechanisms and reaction pathways drawn from kinetic and probe molecules. Photocatalysis and Water Purification: 5372

Montoya JF, Ivanova I, Dillert R, Bahnemann DW, Salvador P, Peral J (2013): Catalytic role of surface oxygens in $\mathrm{TiO}_{2}$ photooxidation reactions: Aqueous benzene

Montoya JF, Peral J, Salvador P (2014): Comprehensive kinetic and mechanistic analysis of $\mathrm{TiO}_{2}$ photocatalytic reactions according to the direct-indirect model:(I) Theoretical approach. The Journal of Physical Chemistry C 118: 14266-14275

Mousavi SM, Mahjoub AR, Abazari R (2017): Facile green fabrication of nanostructural Nidoped $\mathrm{ZnO}$ hollow sphere as an advanced photocatalytic material for dye degradation. J. Mol. Liq. 242: 512-519

Mrowetz M, Selli E (2006): Photocatalytic degradation of formic and benzoic acids and hydrogen peroxide evolution in $\mathrm{TiO}_{2}$ and $\mathrm{ZnO}$ water suspensions. Journal of Photochemistry and Photobiology A: Chemistry 180: 15-22 photocatalytic decolorization of synthetic dyes. The Scientific World Journal 2014

Munter R (2001): Advanced oxidation processes-current status and prospects. Proc. Estonian Acad. Sci. Chem 50: 59-80

Nagao M (1971): Physisorption of water on zinc oxide surface. The Journal of Physical Chemistry 75: 3822-3828

1160

1161

Navarro P, Gabaldón JA, Gómez-López VM (2017): Degradation of an azo dye by a fast and 1162 innovative pulsed light $/ \mathrm{H}_{2} \mathrm{O}_{2}$ advanced oxidation process. Dyes and Pigments 136: 887-892

Norton P, Tapping R, Goodale J (1977): A photoemission study of the interaction of Ni (100),(110) and (111) surfaces with oxygen. Surface Science 65: 13-36

Nosaka Y, Yamashita Y, Fukuyama H (1997): Application of chemiluminescent probe to monitoring superoxide radicals and hydrogen peroxide in $\mathrm{TiO}_{2}$ photocatalysis. The Journal of Physical Chemistry B 101: 5822-5827

Nosaka Y, Nosaka AY (2017): Generation and detection of reactive oxygen species in 1170 photocatalysis. Chem. Rev. 117: 11302-11336 photocatalytic decomposition of phenol over $\mathrm{TiO}_{2}$ powder. Bull. Chem. Soc. Jpn. 58: 1173 2015-2022

Patrick CE, Giustino F (2014): Structure of a water monolayer on the anatase $\mathrm{TiO}_{2}(101)$ surface. Physical Review Applied 2: 014001 
Pelizzetti E, Minero C (1993): Mechanism of the photo-oxidative degradation of organic pollutants over $\mathrm{TiO}_{2}$ particles. Electrochim. Acta 38: 47-55

Peng J, Lu T, Ming H, Ding Z, Yu Z, Zhang J, Hou Y (2019): Enhanced Photocatalytic Ozonation of Phenol by Ag/ZnO Nanocomposites. Catalysts 9: 1006

Qian G, Peng Q, Zou D, Wang S, Yan B (2020): Hydrothermal Synthesis of Flake-Flower $\mathrm{NiO}$ and Its Gas Sensing Performance to CO. Frontiers in Materials 7: 216

Qian R, Zong H, Schneider J, Zhou G, Zhao T, Li Y, Yang J, Bahnemann DW, Pan JH (2019): Charge carrier trapping, recombination and transfer during $\mathrm{TiO}_{2}$ photocatalysis: An overview. Catal. Today 335: 78-90

Rafiee M, Bashiri H (2019): Dynamic Monte Carlo simulations of the reaction mechanism of hydrogen production from formic acid on Ni(1 00$)$. Appl. Surf. Sci. 475: 720-728 1190

Rafiee M, Bashiri H (2020a): Catalytic decomposition of formic acid on $\mathrm{Cu}(100)$ : Optimization and dynamic Monte Carlo simulation. Catal. Commun. 137: $105942 \quad 1192$

Rafiee M, Bashiri H (2020b): Application of response surface methodology and dynamic Monte Carlo simulation to study the hydrogen production from formic acid on $\mathrm{Ni}(100)$. Materials Science and Engineering: B 262: 114729 azo dyes in the presence of $\mathrm{TiO}_{2}$ doped with selective transition metals. Desalination 276: $13-27$

Reddy IN, Reddy CV, Sreedhar A, Shim J, Cho M, Yoo K, Kim D (2018): Structural, optical, and bifunctional applications: Supercapacitor and photoelectrochemical water splitting of Ni-doped ZnO nanostructures. J. Electroanal. Chem124-136:828 .

Reina AC, Santos-Juanes L, Sánchez JG, López JC, Rubio MM, Puma GL, Pérez JS (2015): 1202 Modelling the photo-Fenton oxidation of the pharmaceutical paracetamol in water $\quad 1203$ including the effect of photon absorption (VRPA). Applied Catalysis B: 1204 Environmental 166: 295-301 visible light. Implications of the formation of singlet oxygen $\left({ }^{1} \mathrm{O}_{2}\right)$ under visible light. Applied Catalysis B: Environmental 88: 398-406 trapping and recombination dynamics in small semiconductor particles. Journal of the American Chemical Society 107: 8054-8059

Ryu J, Choi W (2004): Effects of $\mathrm{TiO}_{2}$ surface modifications on photocatalytic oxidation of arsenite: the role of superoxides. Environ. Sci. Technol. 38: 2928-2933 nanoparticles and investigation of dye degradation and cytotoxicity effects. J. Mol. Struct. 1173: 931-936

Safieddine D, Kachenoura A, Albera L, Birot G, Karfoul A, Pasnicu A, Biraben A, Wendling comparison between stochastic (ICA and CCA) and deterministic (EMD and waveletbased) approaches. EURASIP Journal on Advances in Signal Processing 2012: 1-15 
Samadi M, Ahmadi S, Poureshgh Y, Shabanloo A, Rahmani Z, Vanaei Tabar M (2017):

Efficiency of $\mathrm{Mn}_{2} / \mathrm{H}_{2} \mathrm{O}_{2}$ Process in Removal of ReactiveBlue 19 Dyes from Aquatic

Sathishkumar P, Anandan S, Maruthamuthu P, Swaminathan T, Zhou M, Ashokkumar M (2011): Synthesis of $\mathrm{Fe}^{3+}$ doped $\mathrm{TiO}_{2}$ photocatalysts for the visible assisted degradation of an azo dye. Colloids and Surfaces A: Physicochemical and (2014): Understanding $\mathrm{TiO}_{2}$ photocatalysis: mechanisms and materials. Chem. Rev. 114: 9919-9986

Sengunthar P, Bhavsar K, Balasubramanian C, Joshi U (2020): Physical properties and enhanced photocatalytic activity of ZnO-rGO nanocomposites. Appl. Phys. A 126: 19

Shampine LF, Reichelt MW (1997): The matlab ode suite. SIAM journal on scientific

Shams Ghamsari Z, Bashiri H (2020): Hydrogen production through photoreforming of methanol by $\mathrm{Cu}_{(\mathrm{s})} / \mathrm{TiO}_{2}$ nanocatalyst: Optimization and simulation. Surfaces and Interfaces 21: 100709

Simion C, Florea O, Stanoiu A (2017): Gas sensing mechanism involved in $\mathrm{H}_{2} \mathrm{~S}$ detection with $\mathrm{NiO}$ loaded $\mathrm{SnO}_{2}$ gas sensors. SCIENCE AND TECHNOLOGY 20: 415-425 Michael S, Reinhard S (2020): Urea and green tea like precursors for the preparation of $\mathrm{g}-\mathrm{C}_{3} \mathrm{~N}_{4}$ based carbon nanomaterials (CNMs) composites as photocatalysts for photodegradation of pollutants under UV light irradiation. Journal of Photochemistry and Photobiology A: Chemistry: 112596 various dyes by combustion synthesized nano anatase $\mathrm{TiO}_{2}$. Applied Catalysis $\mathrm{B}$ : Environmental 45: 23-38 oxidation processes. Journal of Photochemistry and Photobiology A: Chemistry 353: 26-33

Tamaki Y, Furube A, Murai M, Hara K, Katoh R, Tachiya M (2007): Dynamics of efficient electron-hole separation in $\mathrm{TiO}_{2}$ nanoparticles revealed by femtosecond transient absorption spectroscopy under the weak-excitation condition. Physical Chemistry Chemical Physics 9: 1453-1460 Observation of photocatalytic dissociation of water on terminal Ti sites of $\mathrm{TiO} 2$ (110)-1× 1 surface. Journal of the American Chemical Society 134: 9978-9985 the degradation of tetracycline hydrochloride. Chem. Phys. Lett. 691: 408-414 aspects. Surf. Sci. Rep. 7: 211-385 mechanism via conceptual DFT. Catal. Today 287: 169-175 
Verma AK, Dash RR, Bhunia P (2012): A review on chemical coagulation/flocculation technologies for removal of colour from textile wastewaters. Journal of Environmental Management 93: 154-168

Visan A, van Ommen JR, Kreutzer MT, Lammertink RG (2019): Photocatalytic Reactor Design: Guidelines for Kinetic Investigation. Industrial \& Engineering Chemistry Research 58: 5349-5357

Vittadini A, Casarin M, Selloni A (2007): Chemistry of and on $\mathrm{TiO}_{2}$-anatase surfaces by DFT calculations: a partial review. Theor. Chem. Acc. 117: 663-671

Wageh S, Almazroai LS, Alshahrie A, Al-Ghamdi AA (2018): Enhanced visible light photocatalytic activity of $\mathrm{ZnO}$ and $\mathrm{Ag}$-Doped $\mathrm{ZnO}$ ( $\mathrm{ZnO}: \mathrm{Ag}$ ) nanoparticles. Journal of Nanoscience and Nanotechnology 18: 7682-7690

Wahab HS, Bredow T, Aliwi SM (2008): Computational investigation of water and oxygen adsorption on the anatase $\mathrm{TiO}_{2}\left(\begin{array}{lll}1 & 0 & 0\end{array}\right)$ surface. Journal of Molecular Structure: THEOCHEM 868: 101-108

Walle LE, Borg A, Johansson E, Plogmaker S, Rensmo H, Uvdal P, Sandell A (2011): Mixed dissociative and molecular water adsorption on anatase $\mathrm{TiO}_{2}$ (101). The Journal of Physical Chemistry C 115: 9545-9550

Wan X, Ma R, Tie S, Lan S (2014): Effects of calcination temperatures and additives on the photodegradation of methylene blue by tin dioxide nanocrystals. Mater. Sci. Semicond. Process. 27: 748-757

Wang X-q, Han S-f, Zhang Q-w, Zhang N, Zhao D-d (2018): Photocatalytic oxidation degradation mechanism study of methylene blue dye waste water with $\mathrm{GR} / \mathrm{TiO}_{2}$, MATEC Web of Conferences. EDP Sciences, pp. 03006

Wang Y, Shi R, Lin J, Zhu Y (2010): Significant photocatalytic enhancement in methylene blue degradation of $\mathrm{TiO}_{2}$ photocatalysts via graphene-like carbon in situ hybridization. Applied Catalysis B: Environmental 100: 179-183 reactions of molecular oxygen on the $\mathrm{TiO}_{2}(110)$ surface. Physical Review B 68 : 241402

Xia Y, Wang J, Chen R, Zhou D, Xiang L (2016): A review on the fabrication of hierarchical $\mathrm{ZnO}$ nanostructures for photocatalysis application. Crystals 6: 148

Yao S, Qu F, Wang G, Wu X (2017): Facile hydrothermal synthesis of $\mathrm{WO}_{3}$ nanorods for photocatalysts and supercapacitors. J. Alloys Compd. 724: 695-702 photodestruction of organic substances of dilute concentrations. Catal. Today 58: 133140

Yu JC, Lin J, Lo D, Lam S (2000): Influence of thermal treatment on the adsorption of oxygen and photocatalytic activity of $\mathrm{TiO}_{2}$. Langmuir 16: 7304-7308

Yu L, Wang L, Sun X, Ye D (2018): Enhanced photocatalytic activity of $\mathrm{rGO} / \mathrm{TiO}_{2}$ for the decomposition of formaldehyde under visible light irradiation. Journal of Environmental Sciences 73: 138-146

Yue X, Zhang T, Yang D, Qiu F, Fang J (2018): In situ fabrication dynamic carbon fabrics membrane with tunable wettability for selective oil-water separation. Journal of Industrial and Engineering Chemistry 61: 188-196 systems. The Journal of Chemical Physics 94: 3644-3648 oxidation processes (AOPs) for organic-contaminated soil remediation: A review. Chem. Eng. J. 372: 836-851 
1326

1327 
Tables:

Table 1. The systems used to assess the feasibility of applying the proposed approach to predict the photodegradation of the organic pollutants.

\begin{tabular}{|c|c|c|c|c|c|}
\hline The studied system & [photocatalyst] & [pollutant] & [The other materials] & $\mathrm{pH}$ & Ref. \\
\hline $\begin{array}{c}\text { Acid Orange } 7 / \mathrm{Fe} \text {-doped } \mathrm{TiO}_{2} / \\
\text { UV-light }\end{array}$ & $100 \mathrm{mg} \cdot \mathrm{L}^{-1}$ & $50 \mathrm{mg} \cdot \mathrm{L}^{-1}$ & 3 wt. $\%$ & $3-9$ & $\begin{array}{l}\text { (Han et al. } \\
\text { 2018) }\end{array}$ \\
\hline $\begin{array}{c}\text { Congo Red /Ni-doped } \mathrm{ZnO} / \\
\text { UV-light }\end{array}$ & $0.5 \mathrm{~g} . \mathrm{L}^{-1}$ & $10 \mathrm{mg} . \mathrm{L}^{-1}$ & $\begin{array}{l}\text { Ni-to-Zn weight ratios } \\
(2 \%, 3 \%, 5 \%, \text { and } 10 \%)\end{array}$ & 6 & $\begin{array}{l}\text { (Mousavi et } \\
\text { al. 2017) }\end{array}$ \\
\hline $\begin{array}{c}\text { Tetracycline hydrochloride } \\
\text { /N-doped } \mathrm{TiO}_{2} \text { and N-doped } \\
\mathrm{TiO}_{2} / \mathrm{RGO} / \text { visible light }\end{array}$ & $1 \mathrm{~g} . \mathrm{L}^{-1}$ & $10 \mathrm{mg} \cdot \mathrm{L}^{-1}$ & - & neutral & $\begin{array}{l}\text { (Tang et al. } \\
\text { 2018) }\end{array}$ \\
\hline $\begin{array}{c}\text { Phenol } / \mathrm{ZnO} / \mathrm{O}_{3}, \mathrm{Ag} \text {-doped } \\
\mathrm{ZnO} \text { and } \mathrm{Ag} \text {-doped } \mathrm{ZnO} / \mathrm{O}_{3} / \\
\text { UV-light }\end{array}$ & $0.5 \mathrm{~g} . \mathrm{L}^{-1}$ & $50 \mathrm{mg} . \mathrm{L}^{-1}$ & $\begin{array}{c}{\left[\mathrm{O}_{3}(\text { gas })\right]=10 \mathrm{mg} . \mathrm{L}^{-1}} \\
{[\mathrm{Ag}]=1.5 \mathrm{wt} . \%}\end{array}$ & 6.8 & $\begin{array}{l}\text { (Peng et al. } \\
\text { 2019) }\end{array}$ \\
\hline
\end{tabular}

Table 2. Proposed formulations of the reactive-centers on the photocatalyst surface in contact with the pollutant aqueous solution.

\begin{tabular}{|c|c|}
\hline $\begin{array}{l}\text { The type of } \\
\text { reactive-center }\end{array}$ & Formula \\
\hline RC1 & $\mathrm{M}-\mathrm{OH}, \mathrm{M}-\mathrm{OH}_{2}^{+}, \mathrm{M}-\mathrm{O}^{-}, \mathrm{M}-\mathrm{OH}_{2}, \mathrm{M}-\mathrm{O}_{\text {bridge }} \mathrm{H}-\mathrm{M}$, and $\mathrm{M}-\mathrm{O}_{\text {bridge }}\left(\mathrm{H}_{2} \mathrm{O}\right)-\mathrm{M}$ \\
\hline $\mathbf{R C 2}$ & $\mathrm{A}-\mathrm{OH}, \mathrm{A}-\mathrm{OH}_{2}^{+}, \mathrm{A}-\mathrm{O}^{-}, \mathrm{A}-\mathrm{OH}_{2}, \mathrm{~A}-\mathrm{O}_{\text {bridge }} \mathrm{H}-\mathrm{X}$, and $\mathrm{A}-\mathrm{O}_{\text {bridge }}\left(\mathrm{H}_{2} \mathrm{O}\right)-\mathrm{X}$ \\
\hline $\mathbf{R C 3}$ & $\mathrm{M}-\mathrm{O}_{2}\left(\mathrm{Ti}-\mathrm{O}_{2}\right.$ or $\left.\mathrm{Zn}-\mathrm{O}_{2}\right)$ \\
\hline RC4 & $\mathrm{A}-\mathrm{O}_{2}\left(\mathrm{Fe}-\mathrm{O}_{2}\right.$ or $\mathrm{Ag}-\mathrm{O}_{2}$ or $\left.\mathrm{Ni}-\mathrm{O}_{2}\right)$ \\
\hline RC5 & $B-\mathrm{O}_{2}\left(r G O-\mathrm{O}_{2}\right)$ \\
\hline RC6 & Species adsorbed $(\mathrm{C})$ on the surface of the photocatalyst (such as $\mathrm{O}_{3}$ ) \\
\hline RC7 & The effective reactive-centers such as $\mathrm{Ti}^{4+}$ and $\mathrm{Zn}^{2+}$ for the trapping of photogenerated electrons \\
\hline RC8 & The effective reactive-centers such as $>\mathrm{O}^{2-}$ and $\mathrm{OH}^{-}$for the trapping of photogenerated holes \\
\hline RC9 & $\begin{array}{c}\text { The other effective reactive-centers }\left(\mathrm{A}^{\mathrm{m}+}\right) \text { such as } \mathrm{Fe}^{3+}, \mathrm{Ni}^{2+} \text { and } \mathrm{Ag}^{+} \text {for the trapping of } \\
\text { photogenerated electrons }\end{array}$ \\
\hline RC10 & $S_{\text {inactive }}$ (for hydroxyl radicals) \\
\hline RC11 & $S_{\text {inactive }}$ (for superoxide radicals) \\
\hline RC12 & $S_{\text {inactive }}($ for other species) \\
\hline RC13 & Adsorption sites \\
\hline
\end{tabular}


Table 3. The general proposed framework for the mechanism of the degradation process of the organic pollutants in $\left\{\mathrm{A}-\right.$ doped $\left.\mathrm{M}_{x} \mathrm{O}_{y} / \mathrm{B} / \mathrm{UV}-\mathrm{Vis}\right\}$ aqueous systems.

Part 1: The generation of charge carriers:

$\mathrm{A}-$ doped $\mathrm{M}_{x} \mathrm{O}_{y} / \mathrm{B}+\mathrm{I}_{\mathrm{eff}} \rightarrow \mathrm{h}^{+}+\mathrm{e}^{-}$

Part 2: Adsorption of the organic pollutant on the

photocatalyst surface:

RC7 + pollutant $\leftrightarrows$ pollutant(ads)

Part 3: The trapping of the charge carriers:

$\mathrm{RC} 1+\mathrm{h}^{+} \rightarrow \mathrm{OH}^{\bullet}$ (ads)

$\mathrm{RC} 2+\mathrm{h}^{+} \rightarrow \mathrm{OH}^{\bullet}$ (ads)

$\mathrm{RC} 8+\mathrm{h}^{+} \rightarrow \mathrm{h}_{\text {trapped }}^{+}$

Pollutant(ads) $+\mathrm{h}^{+} \rightarrow$ Intermediates

$\mathrm{RC} 3+\mathrm{e}^{-} \rightarrow \mathrm{O}_{2}^{-\bullet}$ (ads)

$\mathrm{RC} 4+\mathrm{e}^{-} \rightarrow \mathrm{O}_{2}^{-\bullet}$ (ads)

$\mathrm{RC} 5+\mathrm{e}^{-} \rightarrow \mathrm{O}_{2}^{-\bullet}$ (ads)

$\mathrm{RC} 6+\mathrm{e}^{-} \rightarrow \mathrm{O}_{2}^{-\bullet}$ (ads)

$\mathrm{RC7}+\mathrm{e}^{-} \rightarrow \mathrm{e}_{\text {trapped }}^{-}$

$\mathrm{RC} 9+\mathrm{e}^{-} \rightarrow \mathrm{O}_{2}^{-\bullet}$ (ads)

$\mathrm{O}_{2}^{-\bullet}$ (ads) $+2 \mathrm{H}^{+}+\mathrm{e}^{-} \rightarrow \mathrm{H}_{2} \mathrm{O}_{2}$ (ads)

$\mathrm{H}_{2} \mathrm{O}_{2}$ (ads) $+\mathrm{e}^{-} \rightarrow \mathrm{OH}^{\bullet}($ ads $)+\mathrm{OH}^{-}$

Part 4: The reaction of ROSs with the organic pollutant molecules

$\mathrm{OH}^{\bullet}$ (ads) + pollutant $\rightarrow$ Intermediates

$\mathrm{O}_{2}^{-\bullet}$ (ads) + pollutant $\rightarrow$ Intermediates

Part 5: The reaction of ROSs with the intermediates:

Intermediates $+\mathrm{OH}^{\bullet}$ (ads) $\rightarrow$ products

Intermediates $+\mathrm{O}_{2}^{-\bullet}$ (ads) $\rightarrow$ products

Part 6: The recombination of the $\mathrm{e}^{-} / \mathrm{h}^{+}$pairs:

$\mathrm{h}_{\text {trapped }}^{+}+\mathrm{e}_{\text {trapped }}^{-} \rightarrow$ heat

$\mathrm{h}^{+}+\mathrm{e}^{-} \rightarrow$ heat

Part 7: The inactivation of the ROSs by the inactive species:

$\mathrm{RC} 10+\mathrm{OH}^{\bullet}($ ads $) \rightarrow$ Inactivated species

$\mathrm{RC} 11+\mathrm{O}_{2}^{-\bullet}$ (ads) $\rightarrow$ Inactivated species

$\mathrm{RC} 12+$ The other radicals $\rightarrow$ Inactivated species

Table 4. The elementary reaction steps and their rate constants (the fitted results and the reported values in the literature) for the mechanism of the degradation process of the organic pollutants in the studied

The fitted rate constants (k) (Adjusted-optimized)

\begin{tabular}{|c|c|c|c|c|c|c|}
\hline \multirow{2}{*}{\multicolumn{2}{|c|}{ Elementary reactions }} & \\
\hline & & $\begin{array}{c}\text { Fe-doped } \\
\mathrm{TiO}_{2}\end{array}$ & $\begin{array}{c}\text { Ni-doped } \\
\mathrm{ZnO}\end{array}$ & $\begin{array}{c}\text { N-doped } \\
\mathrm{TiO}_{2}\end{array}$ & $\begin{array}{c}\text { N-doped } \\
\mathrm{TiO}_{2} / \text { RGO }\end{array}$ & $\begin{array}{c}\text { Ag-doped } \\
\mathrm{ZnO} / \mathrm{O}_{3}\end{array}$ \\
\hline & $\begin{array}{r}A-\operatorname{doped} M_{x} O_{y} / B / C+I_{e f f} \\
\rightarrow e^{-}+h\end{array}$ & $\begin{array}{c}1.49 \times 10^{-3} \\
\left(\mathrm{M}^{-1} \cdot \mathrm{min}^{-1}\right)\end{array}$ & $\begin{array}{c}1.032 \times 10^{-3} \\
\left(\mathrm{M}^{-1} \cdot \mathrm{min}^{-1}\right)\end{array}$ & $\begin{array}{c}1.18 \times 10^{-1} \\
\left(\mathrm{M}^{-1} \cdot \min ^{-1}\right)\end{array}$ & $\begin{array}{c}1.78 \times 10^{-1} \\
\left(\mathrm{M}^{-1} \cdot \min ^{-1}\right)\end{array}$ & $\begin{array}{c}1.71 \times 10^{-3} \\
\left(\mathrm{M}^{-1} \cdot \mathrm{min}^{-1}\right)\end{array}$ \\
\hline
\end{tabular}


$9.53 \times 10^{7}$

$9.53 \times 10^{7}$

$2.10 \times 10^{9}$

$\left(\mathrm{M}^{-1} \cdot \min ^{-1}\right) \quad\left(\mathrm{M}^{-1} \cdot \min ^{-1}\right)$

$\left(\mathrm{M}^{-1} \cdot \min ^{-1}\right)$

$\left(\mathrm{M}^{-1} \cdot \mathrm{min}^{-1}\right)$

$\left(\mathrm{M}^{-1} \cdot \min ^{-1}\right)$

$6.30 \times 10^{9} \quad 8.30 \times 10^{9}$

$\left(\mathrm{M}^{-1} \cdot \min ^{-1}\right) \quad\left(\mathrm{M}^{-1} \cdot \mathrm{min}^{-1}\right)$

$$
M-O_{2}+e^{-} \rightarrow O_{2 a d s}^{\cdot-}
$$

$\left(\mathrm{M}^{-1} \cdot \min ^{-1}\right)$

$6.20 \times 10^{9}$

$\left(\mathrm{M}^{-1} \cdot \mathrm{min}^{-1}\right)$

\section{$5.49 \times 10^{9}$}

$\left(\mathrm{M}^{-1} \cdot \mathrm{min}^{-1}\right)$

$5.49 \times 10^{9}$

$\left(\mathrm{M}^{-1} \cdot \min ^{-1}\right)$

$\left(\mathrm{M}^{-1} \cdot \min ^{-1}\right)$

$7.30 \times 10^{9}$

$$
A-O_{2}+e^{-} \rightarrow O_{2 a d s}^{\bullet-}
$$

$$
e^{-}+S_{\text {trapping } 1} \rightarrow e_{\text {trapped }}
$$

$$
\mathrm{H}_{2} \mathrm{O}_{2 a d s}+e^{-} \rightarrow \mathrm{OH}_{a d s}^{\bullet}+\mathrm{OH}^{-}
$$

$$
A^{-}+M-O_{2} \rightarrow O_{2 a d s}^{\cdot-}
$$

$\left(\mathrm{M}^{-1} \cdot \mathrm{min}^{-1}\right)$

$7.30 \times 10^{9}$

$\left(\mathrm{M}^{-1} \cdot \mathrm{min}^{-1}\right)$

$$
\mathrm{O}_{3}^{\cdot-}(\text { ads })+\mathrm{H}^{+} \rightarrow \mathrm{HO}_{3}^{\cdot-}(\text { ads })
$$

$$
\mathrm{HO}_{3}^{\bullet^{-}}(\mathrm{ads}) \rightarrow \mathrm{O}_{3}^{\bullet^{-}}(\mathrm{ads})+\mathrm{H}^{+}
$$

pollutant $_{\text {ads }} \rightarrow$ pollutant + Site

$$
\mathrm{HO}_{3}^{\cdot-}(a d s) \rightarrow \mathrm{OH}_{a d s}^{\bullet}+\mathrm{O}_{2}
$$

$$
O_{2 a d s}^{\bullet-}+M-O_{3} \rightarrow O_{3}^{\cdot-}(a d s)
$$

pollutant + Site $\rightarrow$ pollutant $t_{a d s}$

$4.89 \times 10^{9}$ $\left(\mathrm{M}^{-1} \cdot \mathrm{min}^{-1}\right)$

$4.82 \times 10^{9}$ $\left(\mathrm{M}^{-1} \cdot \mathrm{min}^{-1}\right)$

$5.49 \times 10^{9}$ $\left(\mathrm{M}^{-1} \cdot \mathrm{min}^{-1}\right)$

$\left(\mathrm{M}^{-1} \cdot \mathrm{min}^{-1}\right)$

$7.86 \times 10^{9}$

$\left(\mathrm{M}^{-1} \cdot \mathrm{min}^{-1}\right)$

$7.70 \times 10^{9}$ $\left(\mathrm{M}^{-1} \cdot \mathrm{min}^{-1}\right)$<smiles>CCC</smiles>

$1.42 \times 10^{12}$ $\left(\mathrm{M}^{-1} \cdot \mathrm{min}^{-1}\right)$

$1.42 \times 10^{12}$ $\left(\mathrm{M}^{-1} \cdot \mathrm{min}^{-1}\right)$ $\left(\mathrm{M}^{-1} \cdot \min ^{-1}\right)$

\section{$6.53 \times 10^{7}$}

$\left(\mathrm{M}^{-1} \cdot \min ^{-1}\right)$

\section{$2.59 \times 10^{9}$}

$2.59 \times 10^{9}$

$2.53 \times 10^{9}$

$9.53 \times 10^{11}$

$\left(\mathrm{M}^{-1} \cdot \mathrm{min}^{-1}\right)$

$2.30 \times 10^{11}$

$\left(\mathrm{M}^{-1} \cdot \mathrm{min}^{-1}\right)$ $\left(\mathrm{M}^{-1} \cdot \mathrm{min}^{-1}\right)$

$\left(\mathrm{M}^{-1} \cdot \mathrm{min}^{-1}\right)$

$\left(\mathrm{M}^{-1} \cdot \mathrm{min}^{-1}\right)$

$2.53 \times 10^{9}$

$2.80 \times 10^{9}$

\section{$\left(\mathrm{M}^{-1} \cdot \mathrm{min}^{-1}\right)$}

$3.02 \times 10^{9}$

$\left(\mathrm{M}^{-1} \cdot \mathrm{min}^{-1}\right)$ $\begin{array}{ccccc}4 \times 10^{1} & 2.1 \times 10^{2} & 7.92 \times 10^{2} & 1.20 \times 10^{3} & 2.75 \times 10^{2} \\ \left(\mathrm{M}^{-1} \cdot \min ^{-1}\right) & \left(\mathrm{M}^{-1} \cdot \min ^{-1}\right) & \left(\mathrm{M}^{-1} \cdot \min ^{-1}\right) & \left(\mathrm{M}^{-1} \cdot \mathrm{min}^{-1}\right) & \left(\mathrm{M}^{-1} \cdot \mathrm{min}^{-1}\right)\end{array}$

$9.20 \times 10^{8}$

$\left(\mathrm{M}^{-1} \cdot \min ^{-1}\right)$

$-$

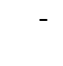

$9.20 \times 10^{8}$ $\left(\mathrm{M}^{-1} \cdot \min ^{-1}\right)$

$9.50 \times 10^{8}$ $\left(\mathrm{M}^{-1} \cdot \mathrm{min}^{-1}\right)$

$3.23 \times 10^{10}$ $\left(\mathrm{M}^{-1} \cdot \min ^{-1}\right)$

$3.45 \times 10^{5}$ $\left(\mathrm{M}^{-1} \cdot \mathrm{min}^{-1}\right)$

$3.20 \times 10^{5}$ $\left(\mathrm{M}^{-1} \cdot \mathrm{min}^{-1}\right)$

$6.00 \times 10^{9}$ $\left(\mathrm{M}^{-1} \cdot \min ^{-1}\right)$

$\begin{array}{ccccc}1 \times 10^{-3} & \begin{array}{c}1.59 \times 10^{2} \\ \left(\min ^{-1}\right)\end{array} & \begin{array}{c}7.50 \times 10^{2} \\ \left(\min ^{-1}\right)\end{array} & \begin{array}{c}8.5 \times 10^{1} \\ \left(\min ^{-1}\right)\end{array} & \begin{array}{c}2.12 \times 10^{2} \\ \left(\min ^{-1}\right)\end{array}\end{array}$

$\begin{array}{lllll}9.20 \times 10^{6} & 5.02 \times 10^{7} & 9.53 \times 10^{7} & 9.53 \times 10^{7} & 8.70 \times 10^{7}\end{array}$

$\left(\mathrm{M}^{-1} \cdot \min ^{-1}\right) \quad\left(\mathrm{M}^{-1} \cdot \min ^{-1}\right) \quad\left(\mathrm{M}^{-1} \cdot \min ^{-1}\right) \quad\left(\mathrm{M}^{-1} \cdot \min ^{-1}\right) \quad\left(\mathrm{M}^{-1} \cdot \mathrm{min}^{-1}\right)$

$\begin{array}{ccccc}5.03 \times 10^{3} & 8.30 \times 10^{4} & 9.53 \times 10^{3} & 3.79 \times 10^{3} & 7.30 \times 10^{3}\end{array}$

$\begin{array}{lllll}\left(\mathrm{M}^{-1} \cdot \min ^{-1}\right) & \left(\mathrm{M}^{-1} \cdot \min ^{-1}\right) & \left(\mathrm{M}^{-1} \cdot \min ^{-1}\right) & \left(\mathrm{M}^{-1} \cdot \min ^{-1}\right) & \left(\mathrm{M}^{-1} \cdot \min ^{-1}\right)\end{array}$

$2.52 \times 10^{2}$

$\left(\mathrm{M}^{-1} \cdot \min ^{-1}\right)$

$\begin{array}{lllll}5.18 \times 10^{6} & 6.90 \times 10^{6} & - & - & 6.68 \times 10^{6}\end{array}$

$\left(\mathrm{M}^{-1} \cdot \min ^{-1}\right) \quad\left(\mathrm{M}^{-1} \cdot \mathrm{min}^{-1}\right) \quad\left(\mathrm{M}^{-1} \cdot \mathrm{min}^{-1}\right)$ 


\begin{tabular}{|c|c|c|c|c|c|c|}
\hline 26 & intermediate $3+O_{2 a d s}^{\bullet-} \rightarrow$ Products & $\begin{array}{c}6.03 \times 10^{3} \\
\left(\mathrm{M}^{-1} \cdot \min ^{-1}\right)\end{array}$ & $\begin{array}{c}5.38 \times 10^{4} \\
\left(\mathrm{M}^{-1} \cdot \mathrm{min}^{-1}\right)\end{array}$ & $\begin{array}{c}9.79 \times 10^{3} \\
\left(\mathrm{M}^{-1} \cdot \min ^{-1}\right)\end{array}$ & $\begin{array}{c}2.11 \times 10^{3} \\
\left(\mathrm{M}^{-1} \cdot \min ^{-1}\right)\end{array}$ & $\begin{array}{c}1.60 \times 10^{3} \\
\left(\mathrm{M}^{-1} \cdot \mathrm{min}^{-1}\right)\end{array}$ \\
\hline 27 & $e_{\text {trapped }}+h_{\text {trapped }} \rightarrow$ heat & $\begin{array}{c}3.56 \times 10^{9} \\
\left(\mathrm{M}^{-1} \cdot \mathrm{min}^{-1}\right)\end{array}$ & $\begin{array}{c}7.86 \times 10^{9} \\
\left(\mathrm{M}^{-1} \cdot \mathrm{min}^{-1}\right)\end{array}$ & - & - & $\begin{array}{c}3.92 \times 10^{8} \\
\left(\mathrm{M}^{-1} \cdot \mathrm{min}^{-1}\right)\end{array}$ \\
\hline 28 & $e^{-}+h^{+} \rightarrow$ heat & $\begin{array}{c}4.59 \times 10^{9} \\
\left(\mathrm{M}^{-1} \cdot \mathrm{min}^{-1}\right)\end{array}$ & $\begin{array}{c}8.90 \times 10^{9} \\
\left(\mathrm{M}^{-1} \cdot \mathrm{min}^{-1}\right)\end{array}$ & $\begin{array}{c}6.48 \times 10^{8} \\
\left(\mathrm{M}^{-1} \cdot \mathrm{min}^{-1}\right)\end{array}$ & $\begin{array}{c}6.45 \times 10^{8} \\
\left(\mathrm{M}^{-1} \cdot \mathrm{min}^{-1}\right)\end{array}$ & $\begin{array}{c}8.30 \times 10^{9} \\
\left(\mathrm{M}^{-1} \cdot \mathrm{min}^{-1}\right)\end{array}$ \\
\hline 29 & $S 1_{\text {inactive }}+O H_{\text {ads }}^{\bullet} \rightarrow$ inactive & $\begin{array}{c}8.00 \times 10^{6} \\
\left(\mathrm{M}^{-1} \cdot \mathrm{min}^{-1}\right)\end{array}$ & $\begin{array}{c}8.00 \times 10^{6} \\
\left(\mathrm{M}^{-1} \cdot \mathrm{min}^{-1}\right)\end{array}$ & - & - & $\begin{array}{c}1.10 \times 10^{7} \\
\left(\mathrm{M}^{-1} \cdot \mathrm{min}^{-1}\right)\end{array}$ \\
\hline 30 & $\begin{array}{l}\mathrm{S} 2_{\text {inactive }}+\mathrm{O}_{2}^{-\bullet} \text { (ads) } \\
\rightarrow \text { Inactivated species }\end{array}$ & - & - & $\begin{array}{c}1.53 \times 10^{3} \\
\left(\mathrm{M}^{-1} \cdot \mathrm{min}^{-1}\right)\end{array}$ & $\begin{array}{c}1.53 \times 10^{3} \\
\left(\mathrm{M}^{-1} \cdot \min ^{-1}\right)\end{array}$ & $\begin{array}{c}6.50 \times 10^{3} \\
\left(\mathrm{M}^{-1} \cdot \mathrm{min}^{-1}\right)\end{array}$ \\
\hline 31 & $\begin{array}{l}\mathrm{S} 3_{\text {inactive }}(\text { ads })+M-\mathrm{C} \\
\rightarrow \text { Inactivated species }\end{array}$ & - & - & - & - & $\begin{array}{c}1.25 \times 10^{2} \\
\left(\mathrm{M}^{-1} \cdot \min ^{-1}\right)\end{array}$ \\
\hline
\end{tabular}

Table 5. The elementary reaction steps and their rate constants (the fitted results and the reported values in the literature) for the mechanism of the $\mathrm{TC}$ degradation in the $\mathrm{TiO}_{2} /$ visible light.

\begin{tabular}{cccc}
\hline I.D. & Elementary reactions & $\begin{array}{c}\text { The adjusted rate constants } \\
\left(\mathrm{M}^{-1} \cdot \mathrm{min}^{-1}\right)\end{array}$ & $\begin{array}{c}\text { The optimized rate constants } \\
\left(\mathrm{M}^{-1} \cdot \mathrm{min}^{-1}\right)\end{array}$ \\
\hline 1 & Site $+\mathrm{TC} \rightarrow \mathrm{TC}($ ads $)$ & $1.12 \times 10^{2}$ & $1.13 \times 10^{2}$ \\
2 & $\mathrm{TC}(\mathrm{ads}) \rightarrow$ Site $+\mathrm{TC}$ & $6.30 \times 10^{1}$ & $6.46 \times 10^{1}$ \\
3 & $\mathrm{TC}(\mathrm{ads})+I_{\text {eff }} \rightarrow \mathrm{TC}(\mathrm{ads})^{*}+\mathrm{e}^{-}$ & $2.70 \times 10^{-4}$ & $1.56 \times 10^{-4}$ \\
4 & $\mathrm{O}_{2}^{-\bullet}+\mathrm{e}^{-} \rightarrow \mathrm{O}_{2}^{-\bullet}($ ads $)$ & $5.49 \times 10^{8}$ & $5.49 \times 10^{8}$ \\
5 & $\mathrm{O}_{2}^{-} \cdot($ ads $)+\mathrm{TC} \rightarrow$ Intermediates & $6.79 \times 10^{3}$ & $6.79 \times 10^{3}$ \\
6 & Intermediates $+\mathrm{O}_{2}^{-\bullet}$ (ads) $\rightarrow$ products & $1.53 \times 10^{4}$ & $1.53 \times 10^{4}$ \\
7 & $\mathrm{TC}(\text { ads })^{*}+\mathrm{e}^{-} \rightarrow$ heat & $6.48 \times 10^{7}$ & $6.48 \times 10^{7}$ \\
8 & $\mathrm{~S}_{\text {inactive }}+\mathrm{O}_{2}^{-\bullet}($ ads $) \rightarrow$ Inactivated species & $1.63 \times 10^{3}$ & $1.63 \times 10^{3}$ \\
\hline
\end{tabular}


Figures:

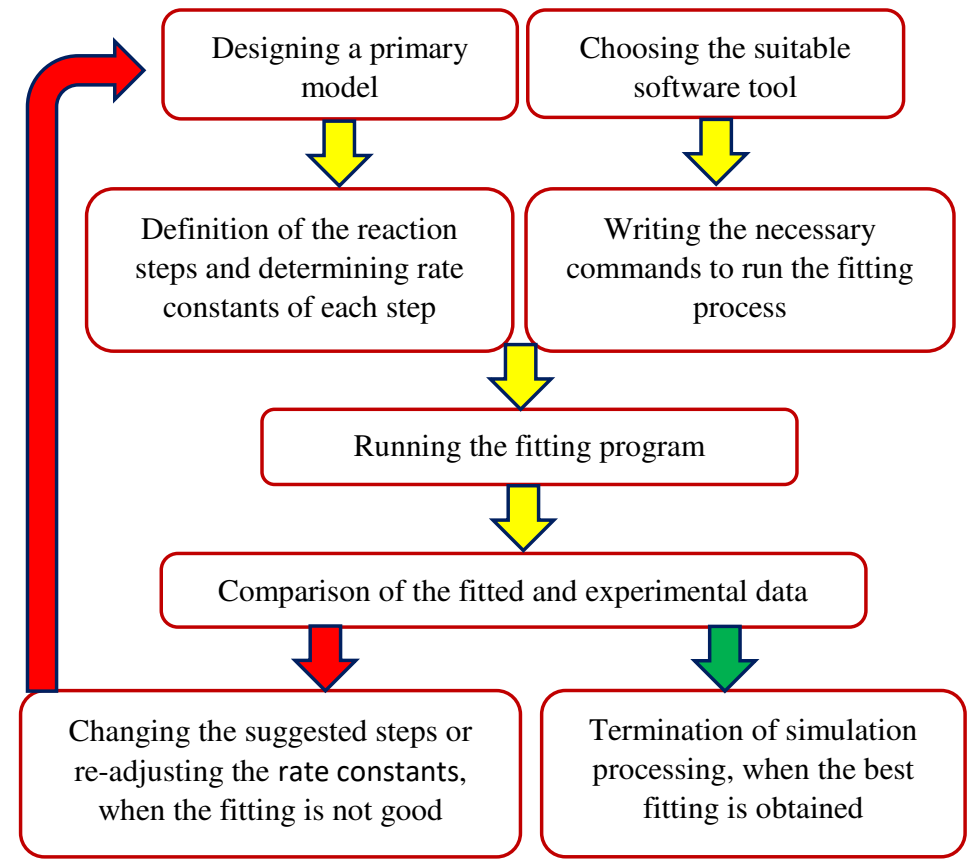

Figure 1. An overview of the proposed approach. 


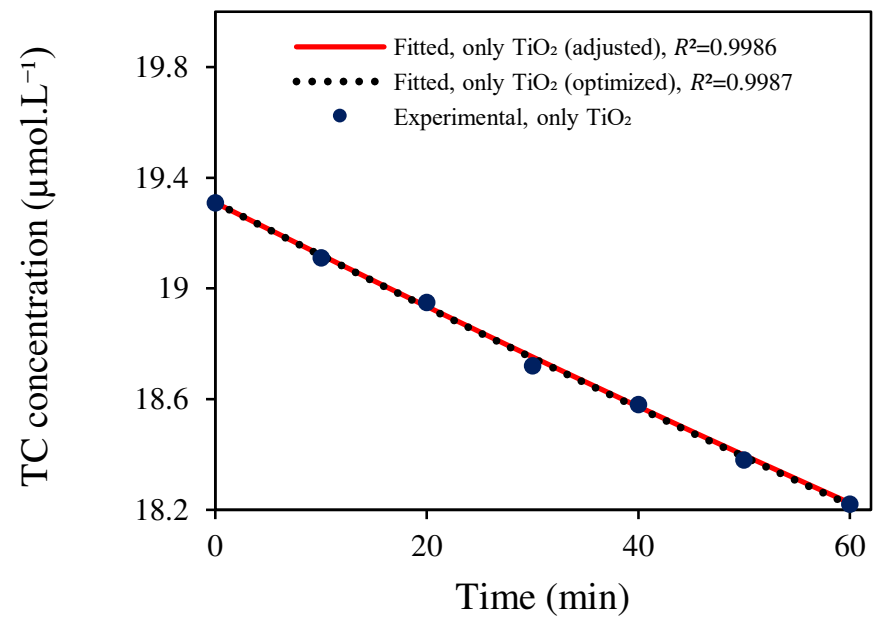

Figure 2. Implementing the proposed approach to find the best mechanism of the TC degradation in the $\mathrm{TiO}_{2}$ /visible-light system by comparing the two optimization and manual adjustment methods. 


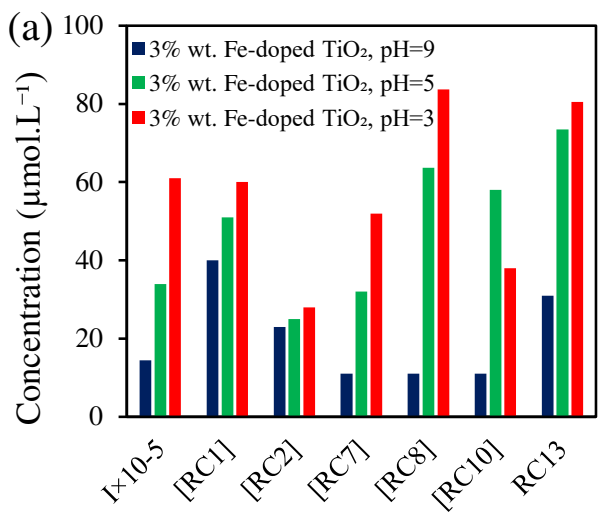

The reactive-centers

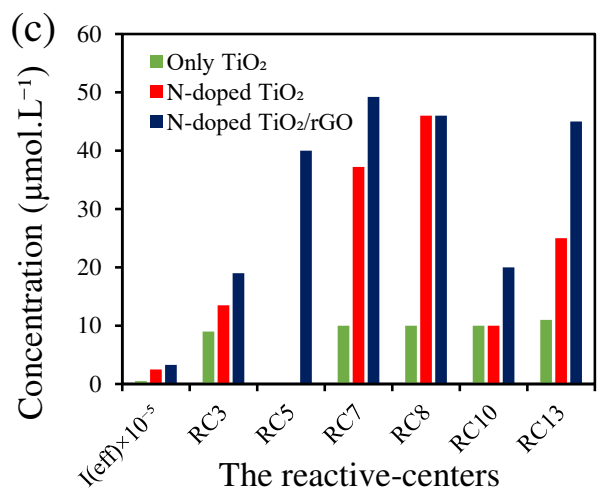

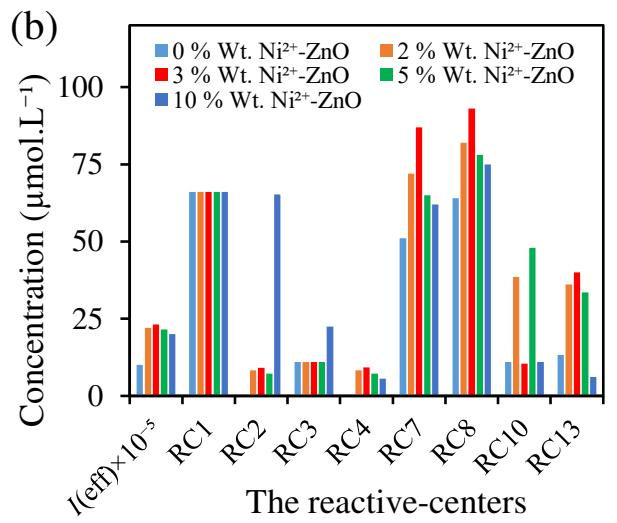

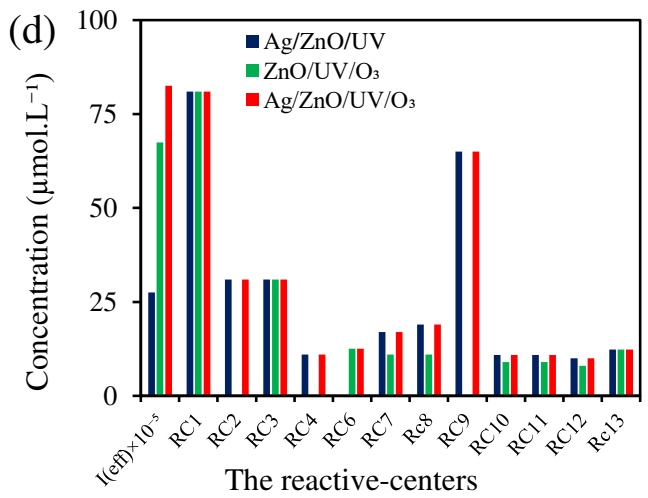

Figure 3. The effective concentration of the reactive-centers obtained from implementing the fitting process for all the studied samples. 

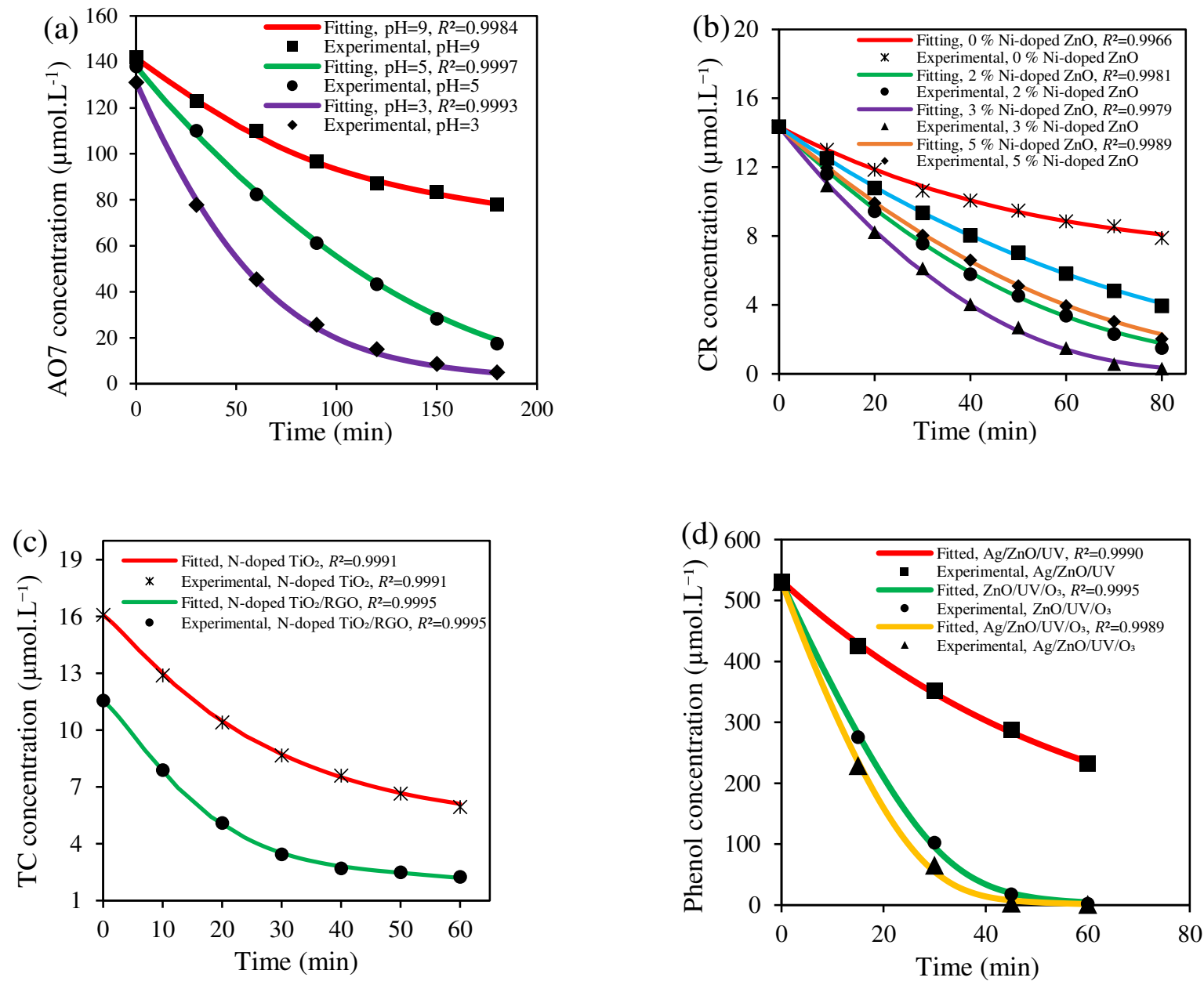

Figure 4. The curves of the organic pollutant concentration vs. time for the studied systems (the experimental and the fitted results). 


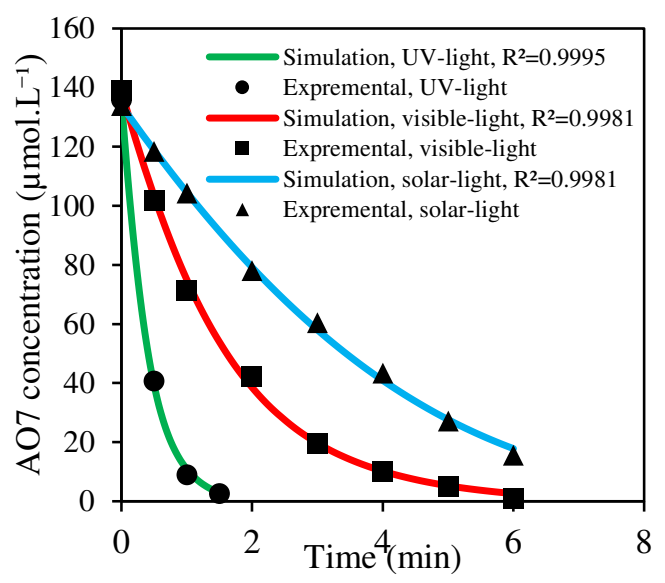

Figure 5. Comparison of the $\mathrm{AO} 7$ photodegradation on the $2 \mathrm{wt} . \% \mathrm{Fe}$-doped $\mathrm{TiO}_{2}$ surface 